\title{
Study on the Mechanical Behavior and Acoustic Emission Properties of Granite under Triaxial Compression
}

\author{
Jiaqi Guo $\mathbb{D}^{1},{ }^{1}$ Pengfei Liu $\mathbb{D}^{1},{ }^{1}$ Junqi Fan $\mathbb{D}^{2},{ }^{2}$ and Hengyuan Zhang $^{1}$ \\ ${ }^{1}$ School of Civil Engineering, Henan Polytechnic University, Jiaozuo 454000, China \\ ${ }^{2}$ Research Institute for National Defense Engineering of Academy of Military Science PLA China, Luoyang 471023, China \\ Correspondence should be addressed to Pengfei Liu; lpf546@163.com
}

Received 8 August 2021; Accepted 26 August 2021; Published 21 September 2021

Academic Editor: Richeng Liu

Copyright (c) 2021 Jiaqi Guo et al. This is an open access article distributed under the Creative Commons Attribution License, which permits unrestricted use, distribution, and reproduction in any medium, provided the original work is properly cited.

\begin{abstract}
To study the rock mechanical behaviors and damage process mechanism of granite samples under triaxial stress, conventional triaxial compression tests were carried out on an RMT-150B rock mechanics testing machine and acoustic emission detector. The test results show that the strength of the granite sample has a good linear relationship with the confining pressure, the cohesion force $c$ of the granite samples is $29.37 \mathrm{MPa}$, and the internal friction angle is $54.23^{\circ}$ by calculation based on the Mohr-Coulomb strength criterion. The larger the initial confining pressure of the rock sample is, the larger the crack initiation stress $\left(\sigma_{\mathrm{ci}}\right)$ and dilatancy stress $\left(\sigma_{\mathrm{cd}}\right)$ of the granite specimen are, the larger the energy values at the crack initiation point and dilatancy point are, and the larger the peak energy storage and energy release rate at the failure are. In the case of a small initial confining pressure, the $\mathrm{AE}$ ringdowning counts and the cumulative $\mathrm{AE}$ ringing counts increase to their maximum instantaneously at the peak stress point, and the damage of the sample develops rapidly. While the initial confining pressure is high, the $\mathrm{AE}$ ringing counts and the cumulative $\mathrm{AE}$ ringing counts of the granite specimens increase evenly, and the deformation damage of the granite specimens is slow. Before the crack initiation point, AE signals are mainly low-energy and low-frequency friction-type AE events, while after the dilatation point, AE signals of samples are mainly high-frequency and high-energy fracture-type AE events. The failure mode of granite samples judged by acoustic emission parameters according to the distribution of characteristic values of AE parameters RA and AF is consistent with the reality. The AE $b$ value of the granite sample is large when the confining pressure is low, and there will be a sudden drop, the decrease time is late, and the decrease rate is large. Under the same stress level, the larger the confining pressure is, the larger the damage variable $D$ is.
\end{abstract}

\section{Introduction}

The stress concentration of surrounding rock in the highstress area caused the energy stored in the rock mass to be released suddenly and violently in the process of underground engineering construction, and eventually, the surrounding rock will fracture loosening, spalling, ejecting and even bursting the rock, and other geological disasters will occur [1-3]. Such geological hazards have seriously threatened the safety, progress, and cost of underground engineering construction $[4,5]$. Meanwhile, the study of the mechanical behavior and damage mechanism of deep buried hard rock under triaxial stress is of great significance for revealing underground engi- neering geological hazards, engineering stability control, and reasonable formulation of prevention and control measures $[6,7]$.

A large number of papers have studied in-depth and systematically researched on the mechanical properties and energy evolution characteristics of rock materials in triaxial compression. Martin and Chandler [8] obtained a complete stress-strain curve and failure mode of the hard rock by a large number of brittle rock load tests using a rigid testing machine. Zong et al. [9] obtained the law that peak strength, elastic modulus, and deformation modulus increase linearly with confining pressure by analyzing the stress-strain characteristics and strength deformation characteristics of 
sandstone. The essence of failure of loaded rock is energy accumulation and release, so it is meaningful to study the law of energy evolution under different mechanical environments to reveal the failure mechanism of rock under load [10-12]. Based on this, Xie et al. [13,14] analyzed the energy evolution mechanism and the influence of energy on rock strength in the failure process of rock under different mechanical states, the internal relationship between rock energy dissipation and release, and the rock strength, and the process of failure was established. Tian and $\mathrm{Yu}$ [15] carried out triaxial compression tests on limestone samples and revealed the energy conversion methods of the rock in each stage of the compression process. Zhang and Gao [16] analyzed the relationship between granite energy characteristics and stress, strain, and confining pressure through triaxial compression tests. The above research result has greatly promoted the development of the research on the energy evolution law in the process of loading failure of hard rock, but the above research has not linked the energy evolution with the fracture damage process of rock.

Acoustic emission monitoring technology is of great significance to study crack propagation and internal damage fracture behavior of brittle materials under complex stresses [17-19]. Eberhardt et al. [20] researched the failure process of granite through acoustic emission monitoring and found that the beginning of significant $\mathrm{AE}$ activity corresponds to the initiation of new cracks. Ganne et al. [21] proposed the four stages of acoustic emission energy accumulation in the rock fracture process through the AE test technology corresponding to the occurrence of microcracks, propagation accumulation, aggregation, and final failure; the material will show obvious characteristics of accelerated energy release before failure. Cai et al. [22] proposed that the frequency of acoustic emission in the spectrogram is related to the size of the fracture. A new method which is called the cumulative AE hit method which has been developed for objective determination of the crack stress was forwarded by Zhao et al. [23]. Zhang et al. [24] studied the variation law of acoustic emission $b$ value of coal rock and showed that the $b$ value would drop rapidly when the rock was failing. Tang and $\mathrm{Xu}$ [25], Eberhardt et al. [26], and Liu et al. [27] used AE events and ringing to characterize the damage of rock and studied the damage evolution law of rock. As can be seen from the above, acoustic emission technology plays an important role in the failure and instability mechanism of rock [28-30]. However, the research is mainly focused on uniaxial compression, and actual rock mass is more in the state of triaxial stress than uniaxial stress. Therefore, researches on acoustic emission characteristics of hard rock under different confining pressures are not in-depth and systematic enough.

To establish the relationship between AE parameters and the failure mechanism of hard rock, and further study the damage evolution law of hard rock under triaxial stress, in this paper, conventional triaxial compression tests under different confining pressures $(5 \mathrm{MPa}, 10 \mathrm{MPa}, 15 \mathrm{MPa}$, and $20 \mathrm{MPa}$ ) for granite specimen were carried out. The mechanical properties and energy evolution mechanism of granite specimens under different confining pressures were studied.
The crack initiation stress $\left(\sigma_{\mathrm{ci}}\right)$ and dilatancy stress $\left(\sigma_{\mathrm{cd}}\right)$ of hard rock were determined based on the law of linear energy dissipation. According to the results of AE monitoring, the characteristics of acoustic damage in the process of hard rock deformation and fracture under different initial confining pressures were studied. The types of granite specimen crack propagation under different loading times were clarified by judging the types of acoustic emission signals. The evolution law of the acoustic emission $b$ value under different confining pressures was studied. The damage model $D$ of granite was established in this paper. The research results of this paper are meaningful to the correct understanding of the mechanical properties and fracture mechanism of hard rock under triaxial stress and provide a theoretical basis for the selection of mechanical parameters of rock mass, engineering design calculation, and selection of support schemes in deep underground engineering.

\section{Experimental Investigations}

2.1. Experimental Instrument and Specimen. Conventional triaxial compression in this paper was carried out by the RMT-150B rock mechanics testing machine (as shown in Figure 1(a)). The instrument can apply a maximum confining pressure of $50 \mathrm{MPa}$, and the maximum axial stress is $1000 \mathrm{kN}$. In this study, the AE events of granite is monitored by DS-5 8-channel in the process of sample loading, as show in Figure 1(b). Meanwhile, in order to avoid attenuation of acoustic signal, butter was used as a coupling agent between the sensor and the sample, as shown in Figure 1(c), and a proper intensifying force was used to ensure good contact between the sensor and the granite sample. The sampling frequency was $3 \mathrm{MHz}$, the threshold value was set as 50 , the amplification factor was set as $40 \mathrm{~dB}$, and the frequency of acoustic emission sensor RS-2A was set as $150 \mathrm{kHz}$ during the acquisition of acoustic emission signals.

The rock mass is complete relatively, without obvious defects, and the surface of the rock looks smooth. The original rock was processed into a cylinder with a diameter of $50 \mathrm{~mm}$ and a height of $100 \mathrm{~mm}$, as shown in Figure 1(d). The machining accuracy of the granite samples was strictly in accordance with the standard of ISRM. The density of the granite is $2.63 \mathrm{~g} / \mathrm{cm}^{3}$ [31]. XRD analysis is widely used to testing the mineral compositions of the rock mass [32]. Therefore, in this study, XRD tests of granite powder were carried out by the Bruker X-ray diffractometer, as shown in Figure 2. Quartz and albite are hard and chemically stable; therefore, the higher the content, the greater the strength of the rock. The content of quartz and albite in the granite sample accounted for $71 \%$, of which albite is $66 \%$ and quartz is $5 \%$. In the sample, laumonite accounted for $25 \%$ and laumontite accounted for $4 \%$.

2.2. Unloading Scheme. The rock sample was wrapped with a latex sleeve before loading; then, rigid cushion blocks with a diameter of $50 \mathrm{~mm}$ and a height of $25 \mathrm{~mm}$ were, respectively, placed on the upper and lower ends of the granite rock sample; finally, the rock sample was put into the pressure cylinder for loading. Rock samples were loaded to 


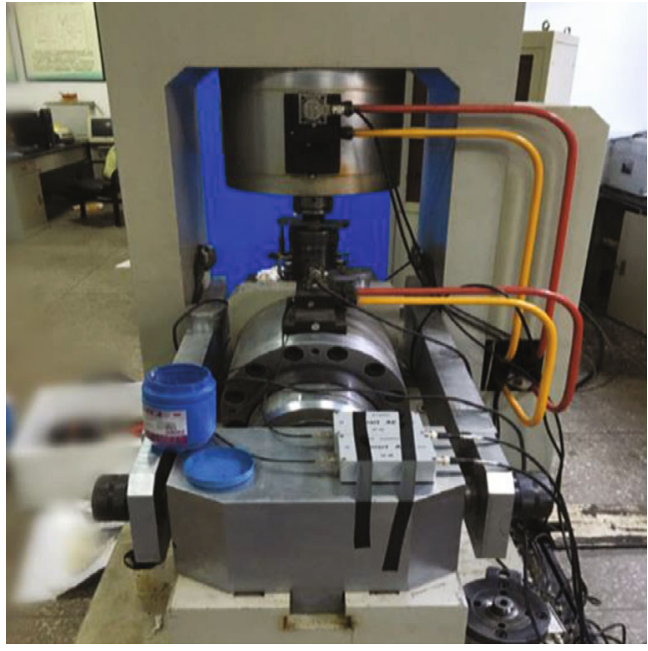

(a) RMT-150B rock mechanics test system

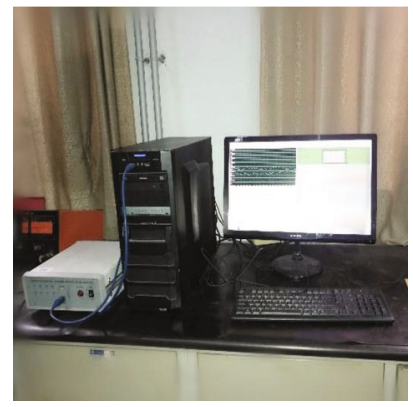

(b) DS-5 AE system

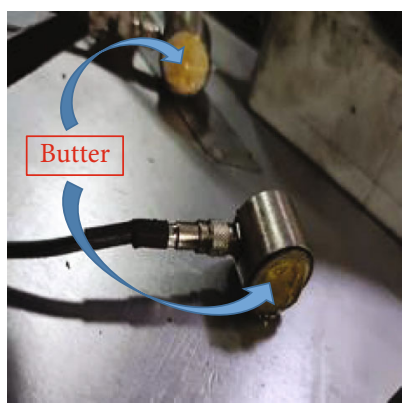

(c) Acoustic emission probe

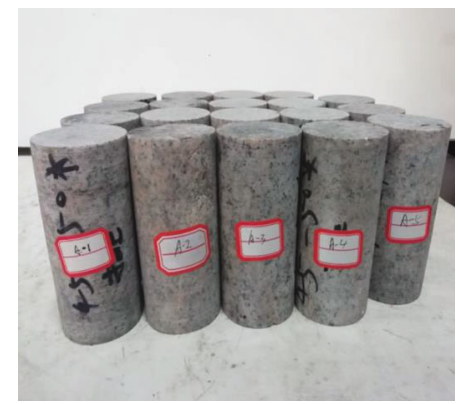

(d) Rock specimens

FIGURE 1: Experimental instruments and rock specimens.

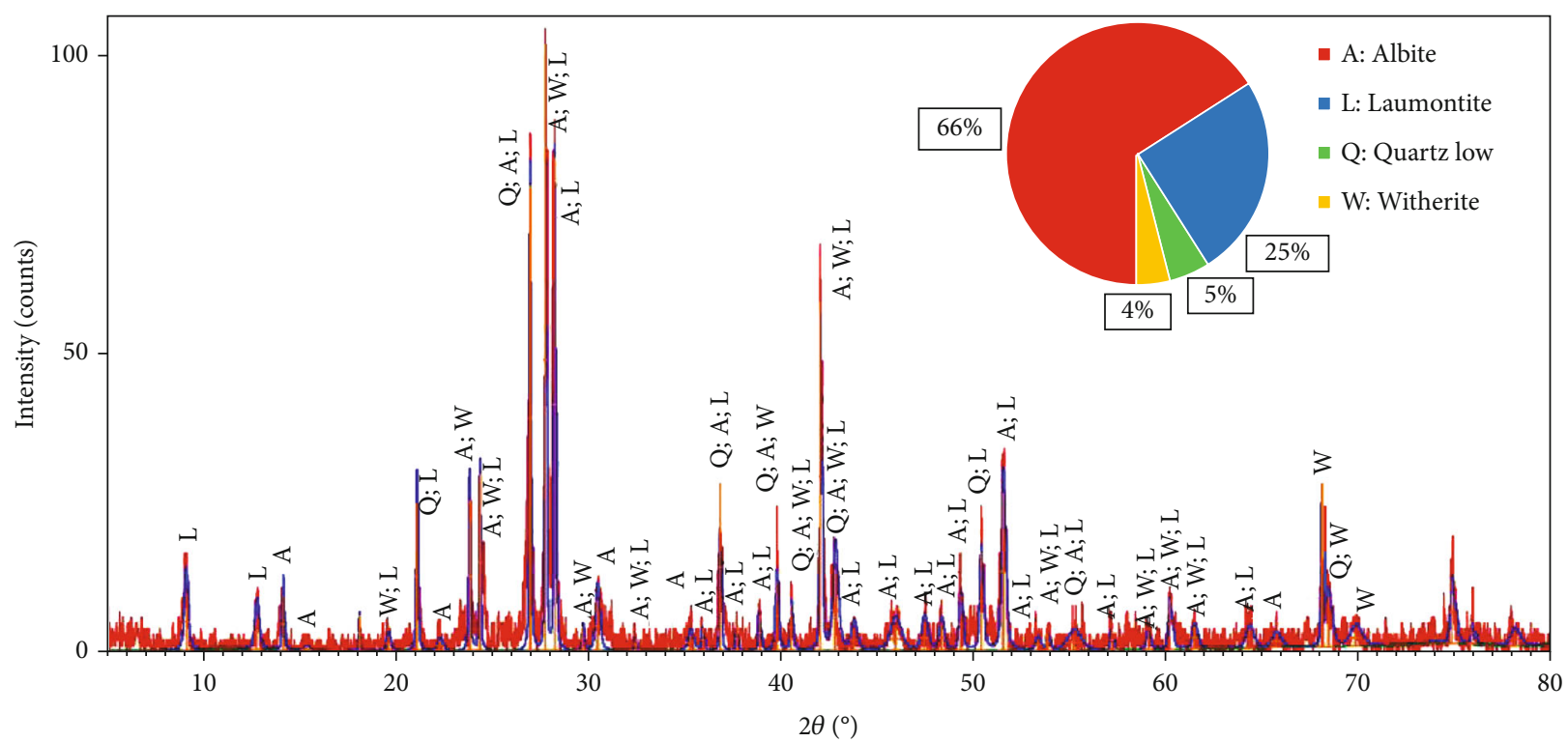

Figure 2: X-ray diffraction patterns of rock samples. 


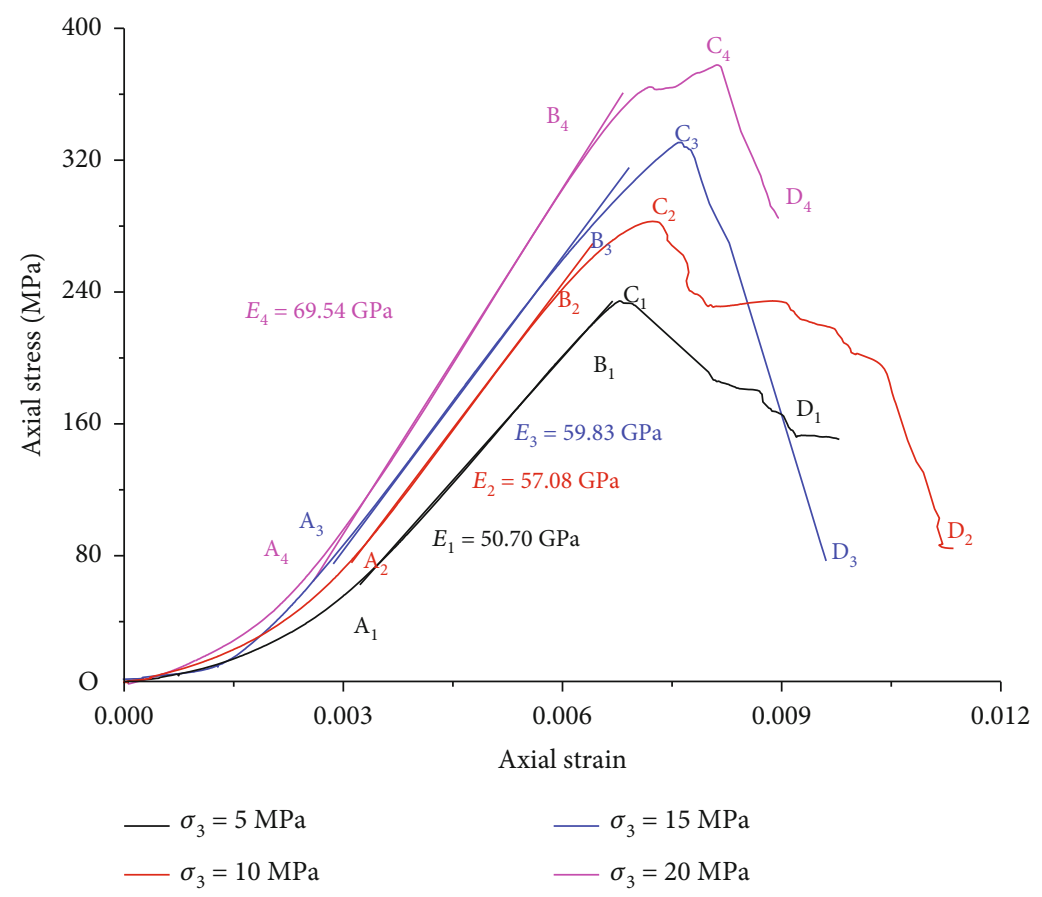

Figure 3: The stress-strain curve of granite.

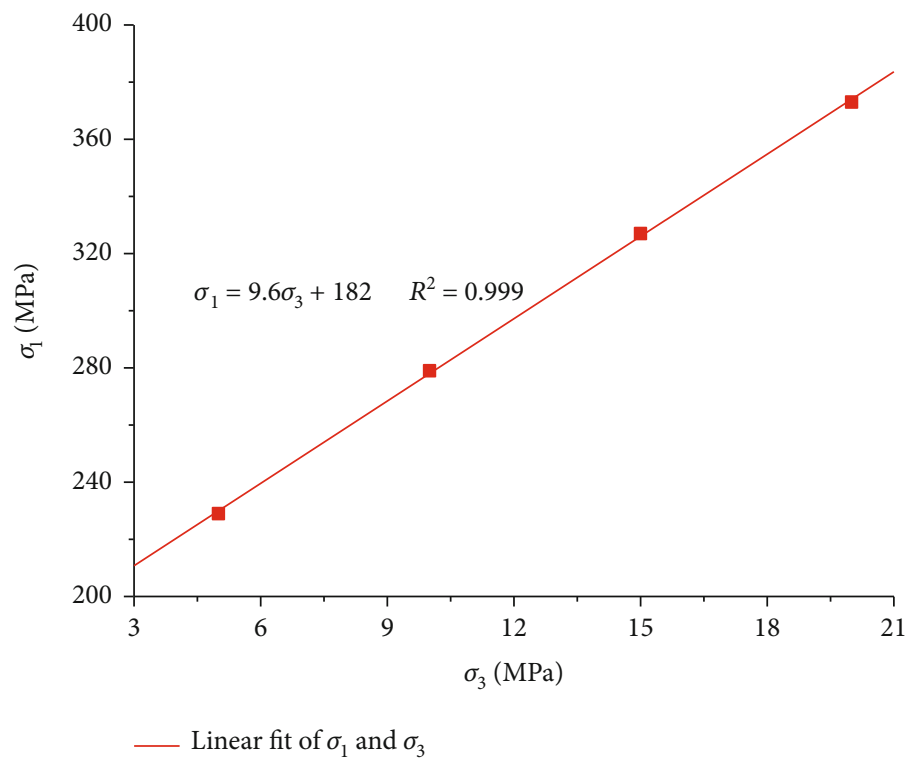

FIGURE 4: Relationship between confining pressures and peak stress.

predetermined confining pressures under hydrostatic pressure, four groups of initial confining pressures (5 MPa, $10 \mathrm{MPa}, 15 \mathrm{MPa}$, and $20 \mathrm{MPa}$ ) were set in this paper, the loading rate of axial stress is $1.00 \mathrm{kN} / \mathrm{s}$, and the loading rate of confining pressure is $0.500 \mathrm{MPa} / \mathrm{s}$ when applied to hydrostatic pressure. And then, axial compression was applied at a constant displacement load rate $(0.005 \mathrm{~mm} / \mathrm{s})$ until rock samples were destroyed.

\section{Experimental Analysis of Mechanical Properties of Granite}

3.1. The Stress-Strain Curves of Granite. The complete stressstrain curves of granite samples under different initial confining pressures are shown in Figure 3.

It can be seen from Figure 3 that the stress-strain curves of the granite samples under different initial confining 


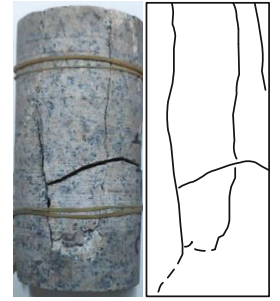

(a) $\sigma_{3}=5 \mathrm{MPa}$

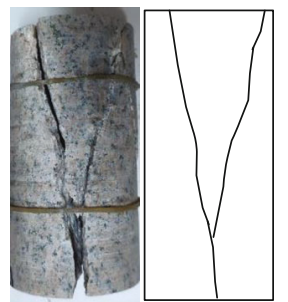

(c) $\sigma_{3}=15 \mathrm{MPa}$

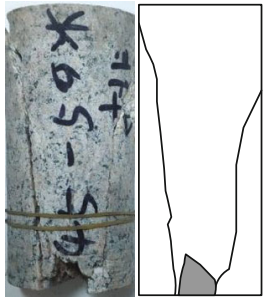

(b) $\sigma_{3}=10 \mathrm{MPa}$

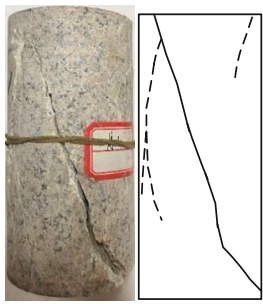

(d) $\sigma_{3}=20 \mathrm{MPa}$

FIgURE 5: Fracture characteristics of granite samples under different confining pressures.

pressures all experienced the compaction stage (OA), linear elastic deformation stage $(\mathrm{AB})$, plastic deformation stage $(\mathrm{BC})$, and postpeak failure stage (CD). In the compaction stage $(\mathrm{OA})$, the original holes and fissures inside the rock sample were compacted, and the stress-strain curves show obvious concaveness. When the sample enters the linear elastic stage $(\mathrm{AB})$, in Figure 3 , the elastic modulus $\left(E_{1}\right)$ of the granite sample is $50.70 \mathrm{GPa}$, and the elastic modulus $\left(E_{4}\right)$ of granite is $69.54 \mathrm{GPa}$, which indicates that the granite sample exhibits significant compression hardening. In the plastic deformation stage (BC), the stress-strain curve of samples becomes concave upward; the greater the confining pressure, the more obvious the prepeak yielding phenomenon and plastic deformation of the sample, and the specimen is gradually transformed from brittle to ductile. With the further application of the axial stress, the samples reach their peak point $(\mathrm{C})$, and the peak stress and peak strain of the granite specimen both increase with the increase of the confining pressure.

3.2. The Strength Characteristics of Granite. Rock strength theory is aimed at expressing the yield and failure laws of rocks under complex stress conditions, which has always been a significant issue in the field of geotechnical engineering. And the Mohr-Coulomb strength criterion is the most authoritative strength theory [33] whose expression is shown in the following formula:

$$
\sigma_{1}=\xi \sigma_{3}+\sigma_{c}
$$

In the formula, $\xi$ is a constant and $\sigma_{c}$ is the uniaxial compressive strength ( $\mathrm{MPa})$. According to formula (1), the fitting results are shown in Figure 4.

It can be seen from Figure 4 that the correlation coefficient $R^{2}$ of the triaxial compression test results fitted is 0.999 , which has a good linear relationship. The parameters $\xi$ and $\sigma_{\mathrm{c}}$ in equation (1) can both be expressed in terms of the strength parameters of the specimen, the cohesion $(\varphi)$, and the angle of internal friction $(c)$, whose expressions are shown in equations (2) and (3) as follows:

$$
\begin{array}{r}
\xi=\frac{1+\sin \varphi}{1-\sin \varphi}, \\
\sigma_{\mathrm{c}}=\frac{2 c \cos \varphi}{1-\sin \varphi},
\end{array}
$$

where $\varphi$ is internal friction of the rock sample $\left(^{\circ}\right)$ and $c$ is the cohesion force of the rock sample $(\mathrm{MPa})$. Based on the fitting results in Figure 4 and equations (2) and (3), the cohesive force $c$ of the granite specimen was calculated to be $29.37 \mathrm{MPa}$ and the angle of internal friction $\varphi$ was $54.23^{\circ}$.

3.3. Failure Characteristics of Granite under Different Confining Pressures. The granite presents a microdrum shape, resulting in an obvious expansion along the transverse direction during the fracture process of conventional triaxial loading. The crack sound of the granite specimen is heard clearly when it fails, which reflects the characteristics of hard rock failure. The photos of fracture characteristics of granite samples are shown in Figure 5.

It can be seen from Figure 5 that near the end of the sample, there are partially fractured surfaces on both sides of the main fracture surface; the end of the rock sample is more severely broken which is caused by the friction effect between the indenter of the testing machine and the end of the rock sample. The main forms of damage of granite specimens in triaxial compression are tensile and shear damage. As shown in Figure 5(a), two axial tensile failure surfaces appear in the rock sample, which shows that the damage of the specimen is compression-induced tensile cracking, and the extension of the tensile crack within the sample plays a dominant role in the damage of the granite specimens when the initial confining pressure is lower. When the initial confining pressure ranges from 10 to $20 \mathrm{MPa}$, 


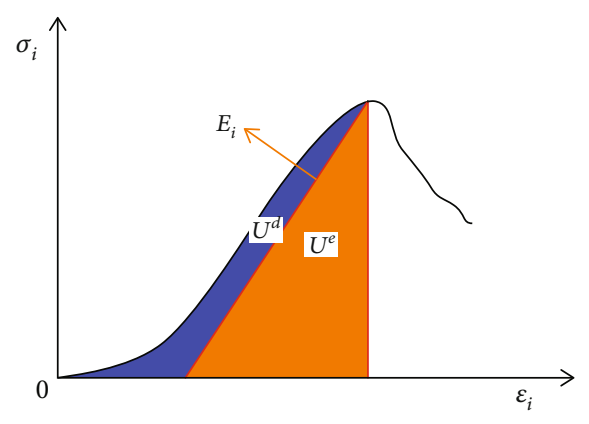

FIGURE 6: Relationship between dissipated energy and releasable strain energy

the failure of the rock sample ends with the formation of a macroscopic shear surface. As shown in Figure 4(b), the granite specimen fractured with a large number of splitting cracks in the axial direction; as shown in Figure 4(c), the rock sample shows typical Y-type conjugate shear failure; and as shown in Figure 4(d), the rock fracture pattern tends to be simplified, and the complex fracture pattern dominated by a tensile fracture gradually transforms into a single shear fracture pattern. Because the mineral particles inside the rock sample are bonded to each other and fit tightly under high pressure, which results in an increase in the cohesion of the granite sample, it is not prone to tensile fracture, and eventually, shear failure occurs. As show in Figure $4(\mathrm{~d})$, the fracture angle of rock sample is $73^{\circ}$, which is close to the theoretical fracture angle of $72.3^{\circ}$ predicted by the Mohr-Coulomb strength criterion $\left(\theta=45^{\circ}+\varphi / 2\right)$.

\section{Energy Evolution of Granite under Different Confining Pressures}

4.1. Principle of Energy Analysis. Rock loading failure is a process accompanied with energy absorption, storage, and dissipation $[34,35]$. Assuming that the thermal energy generated by the external temperature change is not considered, the work done by the external force on the rock system is partly stored as elastic strain energy, and others are dissipated in the form of dissipation energy $[36,37]$ (as show in formula (4) and Figure 6). The rock will be destroyed when the elastic strain energy reaches its energy storage limit, a part of the stored elastic strain energy is converted into surface energy for the generation of new cracks, and the excess energy is used for rock kinetic energy, sound energy, thermal energy, and various kinds of radiation to be release to the outside world in other forms $[14,35]$.

$$
W=U=U_{e}+U_{d}
$$

where $U$ is the density of total energy $\left(\mathrm{MJ} / \mathrm{m}^{3}\right), U_{e}$ is the density of elastic strain energy $\left(\mathrm{MJ} / \mathrm{m}^{3}\right)$, and $U_{d}$ is the density of dissipated energy $\left(\mathrm{MJ} / \mathrm{m}^{3}\right)$. The schematic diagram of the relationship between the elastic strain energy $U_{e}$ as shown in Figure 6.
Conventional triaxial compression tests were carried out in this paper, Therefore, it can be concluded that $\sigma_{2}=\sigma_{3}$, formula (5) gives the calculation method of total energy $U$ as follows:

$$
\begin{gathered}
U=\int_{0}^{\varepsilon_{1}} \sigma_{1} d \varepsilon_{1}+\int_{0}^{\varepsilon_{2}} \sigma_{2} d \varepsilon_{2}+\int_{0}^{\varepsilon_{3}} \sigma_{3} d \varepsilon_{3}=\int_{0}^{\varepsilon_{1}} \sigma_{1} d \varepsilon_{1}+2 \int_{0}^{\varepsilon_{3}} \sigma_{3} d \varepsilon_{3}, \\
U_{e}=\frac{1}{2 E_{i}}\left[\sigma_{1}^{2}+\sigma_{2}^{2}+\sigma_{3}^{2}-2 \mu\left(\sigma_{1} \sigma_{2}+\sigma_{2} \sigma_{3}+\sigma_{1} \sigma_{3}\right)\right] \\
\approx \frac{1}{2 E_{0}}\left[\sigma_{1}^{2}+2{\sigma_{3}}^{2}-2 \mu\left(\sigma_{1} \sigma_{3}+2 \sigma_{3}^{2}\right)\right], \\
U_{d}=U-U_{e},
\end{gathered}
$$

where $E_{i}$ is the elastic modulus at unloading; it can be replaced by the elastic modulus $E_{0}$ in the calculation [14].

4.2. Energy Evolution Process under Different Confining Pressures. According to formulas (5), (6), and (7), the evolution laws of total energy $U$, elastic strain energy $U_{e}$, and dissipated energy $U_{d}$ of granite specimen during loading and damage under conventional triaxial stress path are obtained by using Origin software, as shown in Figure 7. Based on the conventional triaxial stress-strain characteristics of the sample, the stress-strain curve can be divided into the initial compression stage $(\mathrm{OA})$, elastic deformation stage $(\mathrm{AB})$, stable fracture growth stage $(\mathrm{BC})$, unstable fracture growth stage (CD), and failure stage (DE).

(1) Initial compression stage (OA): the energy absorbed by the rock sample is basically transformed into the dissipated energy $U_{d}$ that causes the microcracks inside the rock to close and frictionally slip, at which point there is essentially no stored energy within the sample.

(2) Elastic deformation stage ( $A B)$ : the original cracks of the sample were compacted; there is no energy dissipation phenomenon in the rock sample. The elastic strain energy stored increases with the occurrence of elastic deformation, and the increase in elastic strain energy is constant. In this stage, the higher the confining pressure is, the higher the elastic strain energy storage rate is.

(3) Stable fracture growth stage (BC): at this stage, the energy is still continuously inputted to the specimen, and the input energy is mainly stored in the form of releasable strain energy. There is a large number of microcracks in the sample initiation and development, but the initiation speed of microcracks in the sample is stable at this time, so the internal dissipation energy of the sample increases linearly at this stage. The crack initiation stress and dilation stress of the sample can be determined by the law of linear energy dissipation (as show in Figure 7). According to Figures $7(\mathrm{a})$ and $7(\mathrm{~b})$, the crack initiation stress and dilatancy stress of granite samples increase with the increase of confining pressure. 


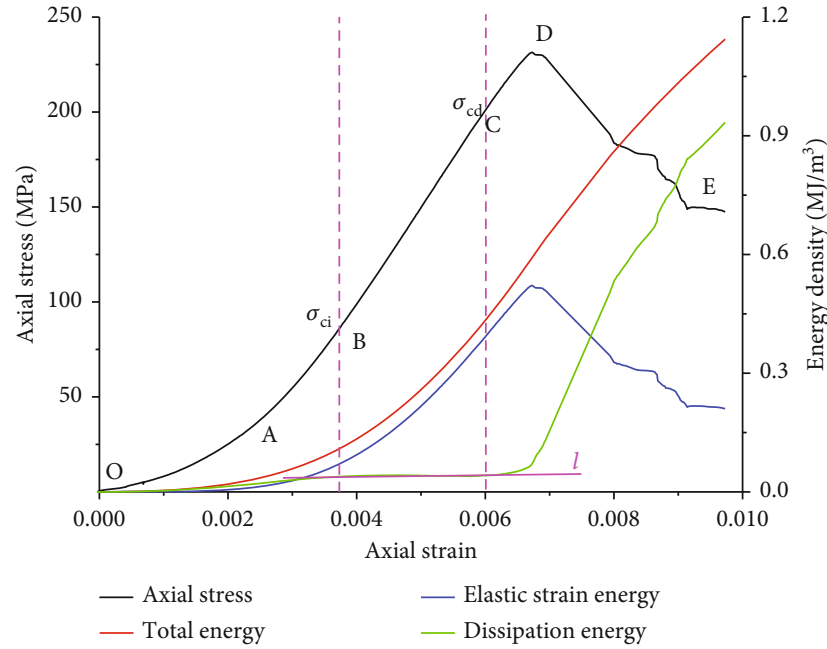

(a) $\sigma_{3}=5 \mathrm{MPa}$

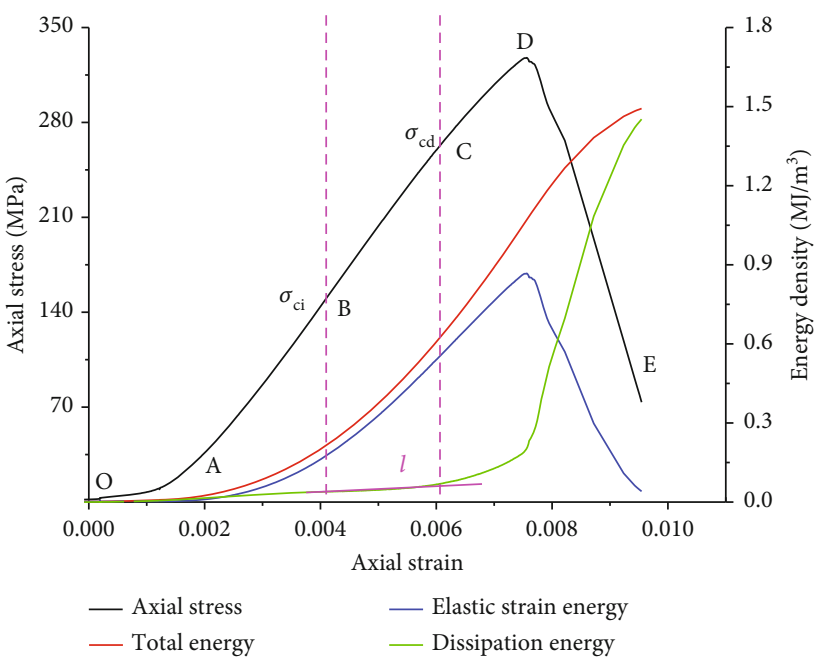

(c) $\sigma_{3}=15 \mathrm{MPa}$

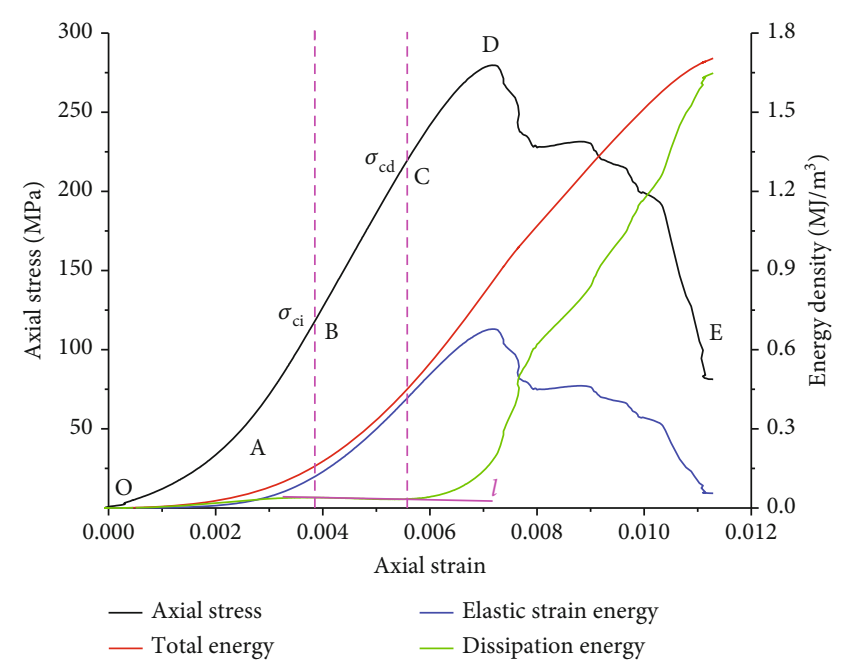

(b) $\sigma_{3}=10 \mathrm{MPa}$

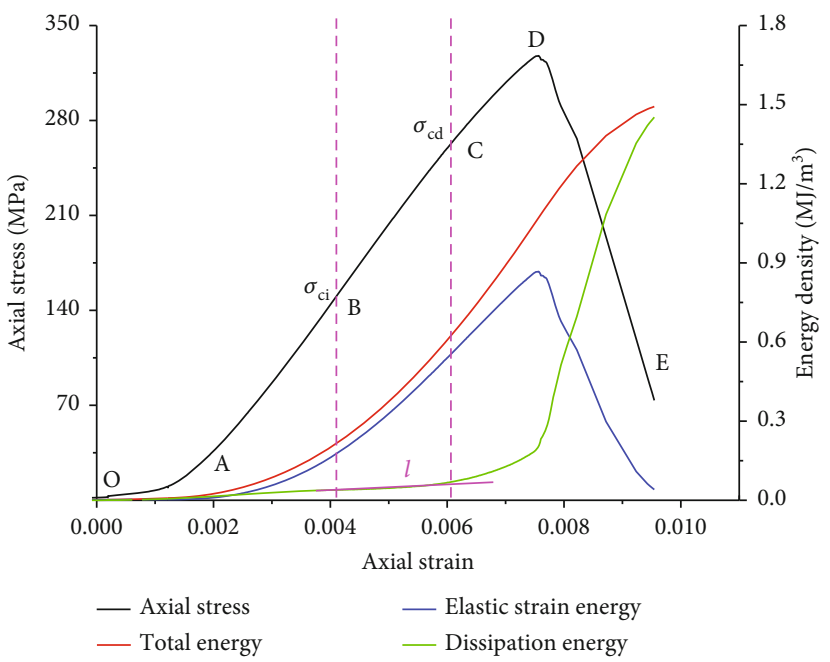

(d) $\sigma_{3}=20 \mathrm{MPa}$

FIGURE 7: Energy evolution characteristics of granite under different confining pressures.

(4) Unstable fracture growth stage (CD): the microcracks inside the rock sample begin to accelerate expansion and penetrate. The growth rate of elastic energy decreases sharply, and the growth rate of dissipated energy increases gradually. At the end of the unstable fracture growth stage, the elastic strain energy reaches the energy storage limit of the specimen, and the dissipation energy increases significantly.

(5) Failure stage (DE): the sample can still absorb energy from the outside after the axial stress reaches its peak stress. However, at this time, the elastic strain decreased sharply, and the dissipated energy increases rapidly due to plastic deformation, macroscopic crack penetration, and slippage dislocation of macroscopic cracks which dissipate a large amount of energy. Finally, the strength of the whole rock structure is lost, and the rock is destroyed. At this stage, the greater the confining pressure is, the faster the energy release rate of the granite sample is. In Figure 7(a), the energy release rate of the granite sample is $377.69 \mathrm{MJ} / \mathrm{m}^{3}$, and in Figure 7(d), the energy release rate of the granite sample is $904.92 \mathrm{MJ} / \mathrm{m}^{3}$.

4.3. Analysis of Energy at Characteristic Points. The threshold stress of the granite sample was determined according to the law of linear energy dissipation in Section 3.2, and the relationship between the confining pressure of the sample and the total energy, elastic strain energy, and dissipated energy was obtained at the threshold stress and peak stress point, as shown in Figure 8.

According to Figure 8, each energy of the specimen under different times is highly correlated with the confining pressure. (1) At the crack initiation point, the confining pressure has a greater impact on the total energy $U$ and elastic strain energy $U_{e}$ of the granite specimen. The energy 


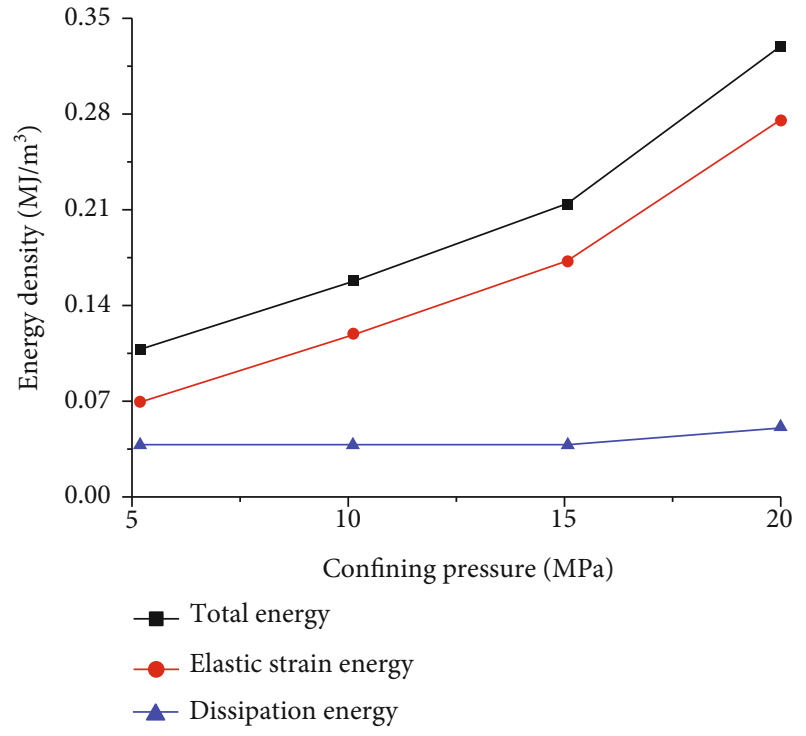

(a) Crack initiation point

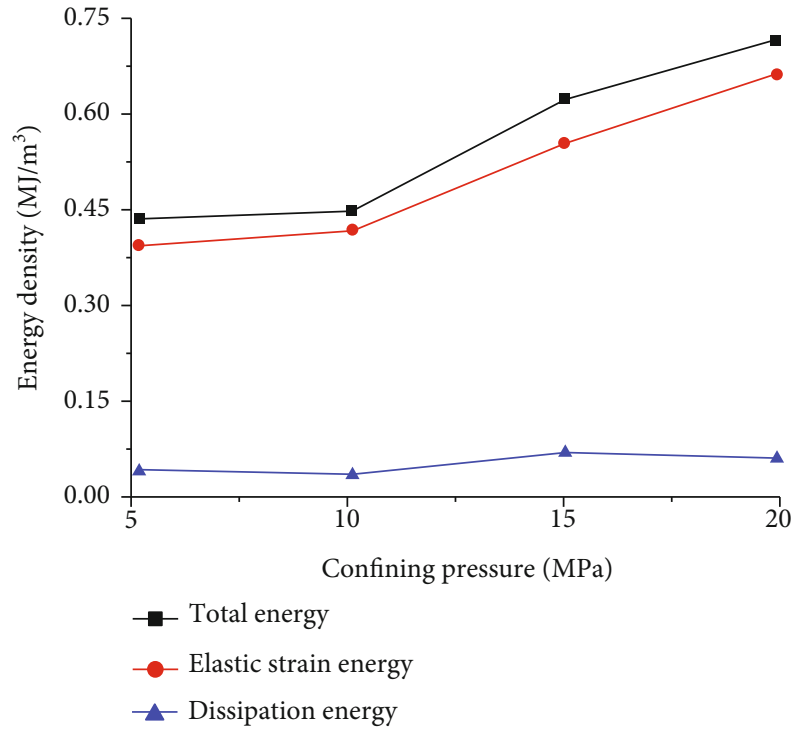

(b) Dilatancy point

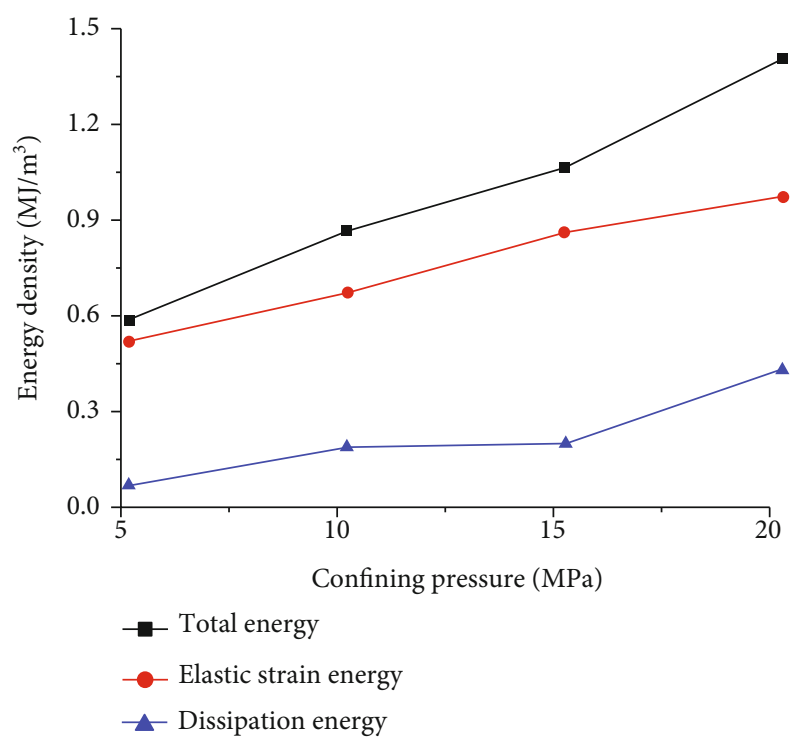

(c) Peak stress point

Figure 8: The relationship between confining pressure and energy at different characteristic points.

absorbed and stored by the sample increases linearly, and its growth rate is $0.011\left(\mathrm{MJ} / \mathrm{m}^{3}\right) / \mathrm{MPa}$, while the change trend of absorbed and stored energy with confining pressure is steep, which is only $0.023\left(\mathrm{MJ} / \mathrm{m}^{3}\right) / \mathrm{MPa}$ when the confining pressure is greater than $15 \mathrm{MPa}$. The change of dissipated energy at the crack initiation point is not significant, and the value of dissipated energy is both $0.039 \mathrm{MJ} / \mathrm{m}^{3}$. (2) At the expansion point, when the confining pressure is less than $10 \mathrm{MPa}$, the change trend of total energy and elastic strain energy of granite sample is slow, and the energy growth rate is $0.002\left(\mathrm{MJ} / \mathrm{m}^{3}\right) / \mathrm{MPa}$ and $0.005\left(\mathrm{MJ} / \mathrm{m}^{3}\right) / \mathrm{MPa}$, respectively. However, the growth rates of total energy and elastic strain energy are $0.027\left(\mathrm{MJ} / \mathrm{m}^{3}\right) / \mathrm{MPa}$ and $0.022\left(\mathrm{MJ} / \mathrm{m}^{3}\right) / \mathrm{MPa}$, respectively, when the confining pressure is larger. At this time, the change of dissipated energy is still not significant; the dissipated energy is both $0.039 \mathrm{MJ} / \mathrm{m}^{3}$. (3) At the peak point, the overall linear law of the total energy, elastic strain energy, and confining pressure of the granite sample is more significant; when the confining pressure is larger than $15 \mathrm{MPa}$, the dissipated energy of the sample increases significantly. As shown in Figures 8(b) and 8(c), the greater the confining pressure is, the more energy is dissipated by the granite sample in the process of damage and failure, and the damage deformation of the sample is sufficient relatively. A large amount of energy was absorbed in the rock specimen when the confining pressure is high. At this time, the limit energy storage capacity of the rock sample is reduced. Therefore, the sample will release a large amount of energy and have a large energy 


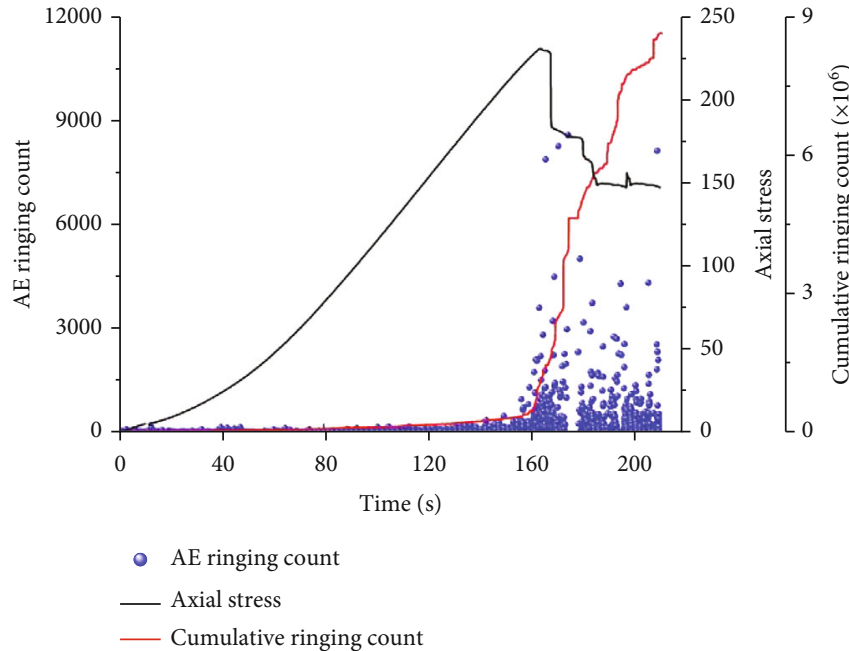

(a) $\sigma_{3}=5 \mathrm{MPa}$

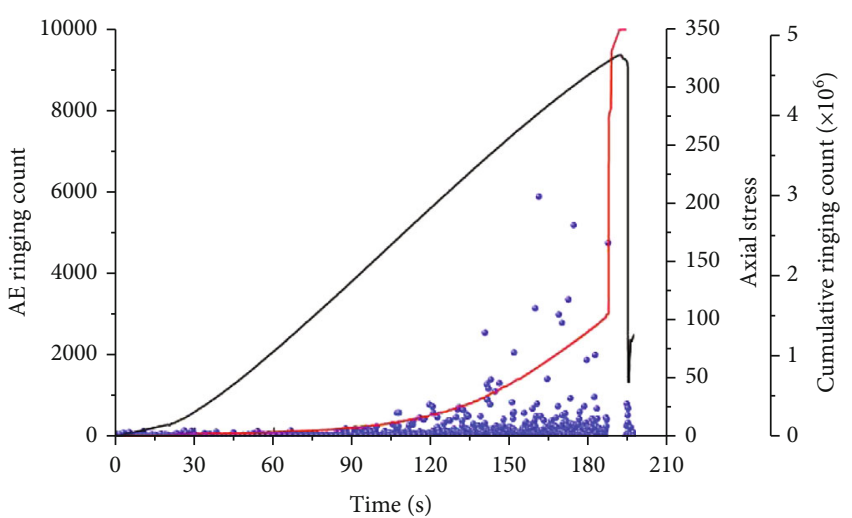

- AE ringing count
- Axial stress
_ Cumulative ringing count

(c) $\sigma_{3}=15 \mathrm{MPa}$

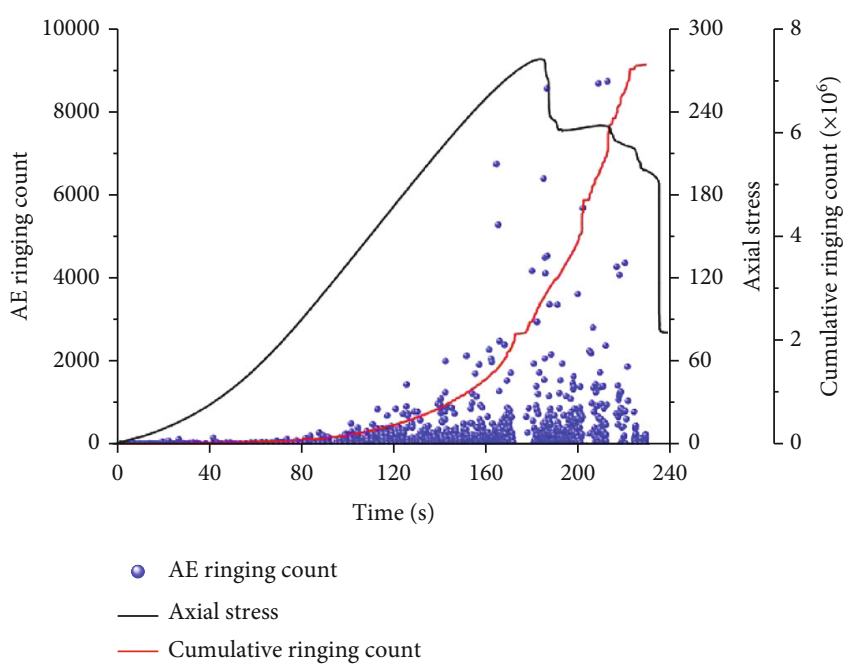

(b) $\sigma_{3}=10 \mathrm{MPa}$

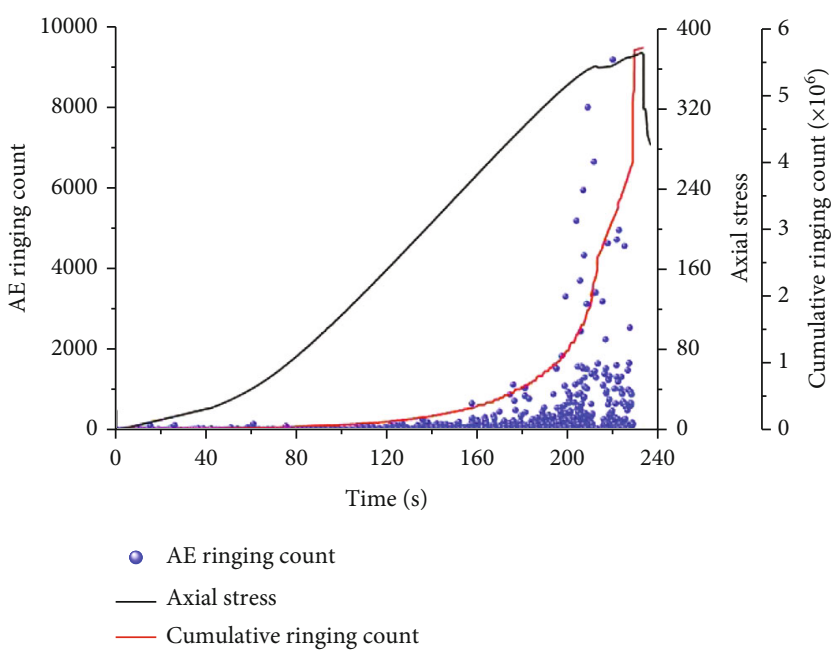

(d) $\sigma_{3}=20 \mathrm{MPa}$

FIGURE 9: AE ringing count characteristics of granite specimens.

release rate when it is broken. This phenomenon has been confirmed in dynamic disasters such as rock bursts during the construction of a high geostress environment of underground engineering.

\section{Damage Analysis of Hard Rock with AE Parameters}

Acoustic emission of rock is an elastic wave released by the propagation of original cracks and defects in rock materials and the formation, initiation, evolution, expansion, and fracture of new microcracks during the process of loading [38, 39]. The acoustic emission of rock contains the evolution information of the failure process inside the rock, and the rock will show different acoustic emission signals and crack propagation characteristics under different stress levels. The analysis of the relationship between the acoustic emission signals and the characteristics of crack propagation in the process of rock fracture is helpful to the study of the internal fracture mechanism of rock under the three-direction stress path, which is of great significance to the further prediction and prevention of rock mass disasters [40, 41].

\subsection{Qualitative Damage Analysis of Hard Rock with AE Parameters}

5.1.1. The AE Ring Count Characteristics of Granite. Acoustic emission technology is of great significance to the study of material damage and fracture processes. Ringing count is a parameter that can better reflect the changes in material damage and fracture processes among many acoustic emission parameters, because it is proportional to the strain energy released by dislocation movement, inclusion and second phase particle peeling, and fracture and crack propagation in the rock material $[18,19]$. Figure 9 shows AE ringing counts and cumulative ringing counts in the deformation and failure process of granite samples.

It can be seen from Figure 9, at the initial loading stage, there were small amounts of AE events in the granite specimen during the compaction stage due to the original cracks 

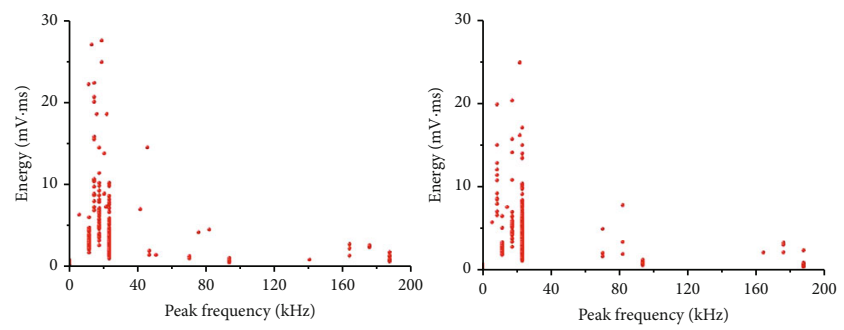

(a) Moment $\mathrm{A}$
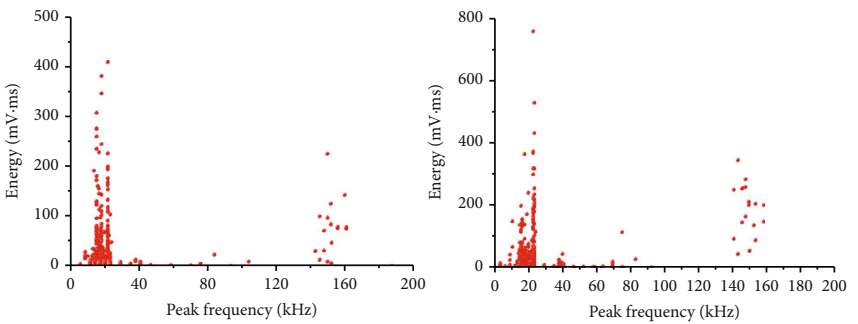

(c) Moment C

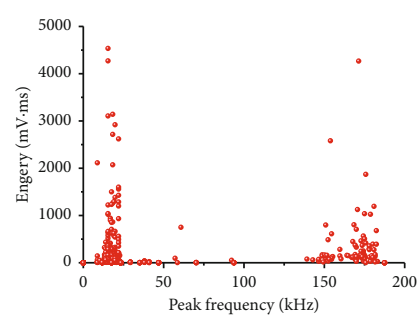

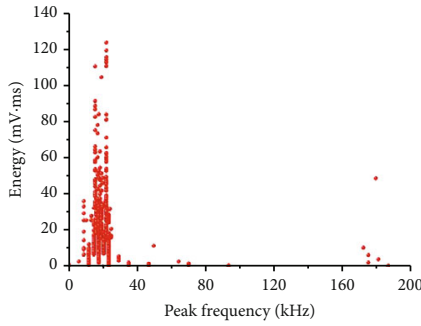

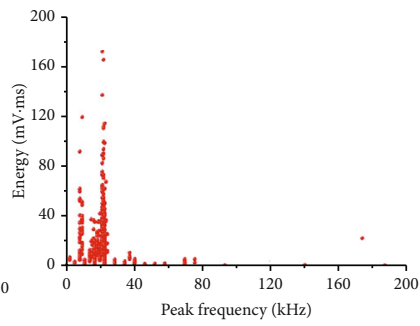

(b) Moment B
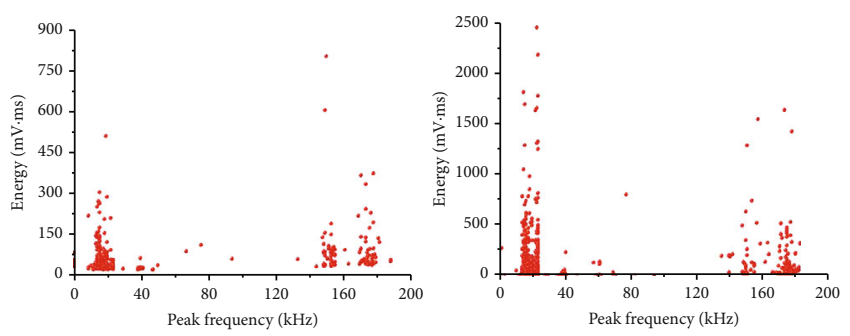

(d) Moment D

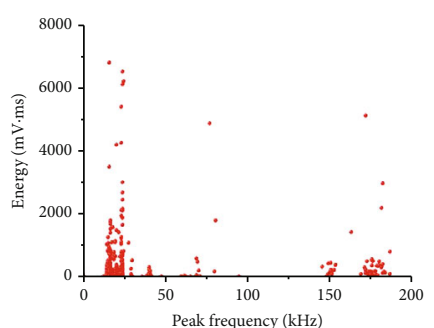

(e) Moment E

FIGURE 10: The relationship between peak frequency and energy under different moments.

inside the sample beginning to close and the frictional effect of rough crack surfaces occurring. With continuous loading, the sample enters the elastic deformation stage; at this time, acoustic emission events are still rare, because the stress in the granite specimen is not enough to product new cracks, and the generation of acoustic emission events is caused by the dislocation and grain slip between closed microcrack surfaces. When the sample enters the stage of stable microcrack growth, the cracks in the sample initiate, bifurcate, and develop stably, and the old cracks also enter the state of stable development. Acoustic emission events in the sample begin to increase, and the cumulative ringing count increases linearly. With the further application of axial load, internal microcracks of the sample accelerate extension, aggregation, and penetration; the acoustic emission event of the sample becomes active; and the cumulative ringing count curve is concave. At the peak stress, $\mathrm{AE}$ events are hyperactive, the $\mathrm{AE}$ ringing counts reach their maximum value, and the cumulative ringing counts increase suddenly.

When the confining pressure is small (see Figure 9(a)), the $\mathrm{AE}$ ringing counts are small in the prepeak stage, and the cumulative ringing count is only $0.46 \times 10^{6}$. The cumulative ring count increases sharply from $0.46 \times 10^{6}$ to 6.27 $\times 10^{6}$ from the peak point to the failure process of the sample. When the confining pressure is large (see Figure $9(\mathrm{~d})$ ), the AE activity of the sample is relatively active before it fractures, and its cumulative ringing count has reached $2.24 \times 10^{6}$. In the case of low confining pressure, the granite specimen undergoes brittle failure when the axial stress reaches it material strength; therefore, the AE ringing counts increase to its maximum value instantaneously in the failure stage; on the contrary, the axial stress reaches the strength of the rock material and plastic deformation occurs. However, the strength of the rock material is greatly enhanced due to the confining pressure effect. At this time, the specimen still has a strong bearing capacity, the internal damage of the sample continues to develop, and the load-bearing capacity of the sample is gradually reduced while the deformation increases gradually. Finally, the specimen reaches its ultimate bearing capacity at the peak stress and ductile failure occurs; the acoustic emission ringing count grows more evenly in this process.

\subsubsection{Acoustic Emission Types under Different Confining} Pressures and Moments. Acoustic emission ringing count can qualitatively reflect the degree of the internal damage of the sample during the conventional triaxial loading failure process, and the type of acoustic emission signal can be judged by the frequency and energy of the acoustic emission signal, which can further investigate the type of damage within the specimen. There are two types of AE events in the process of rock deformation and damage under stress 


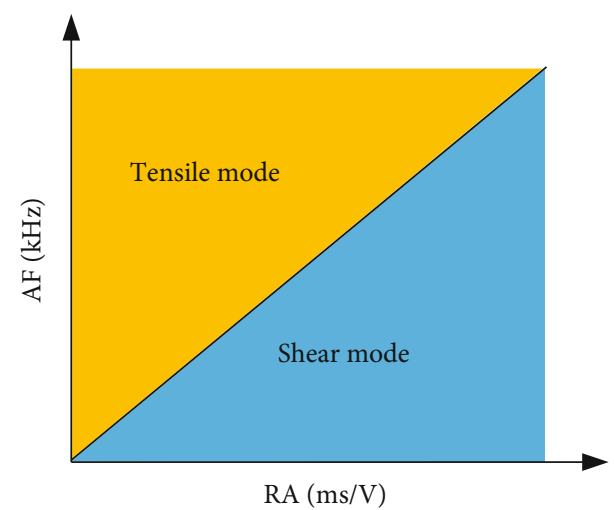

FIgURE 11: Relationship between RA value and AF value.

[42]. The first is the friction-type acoustic emission event caused by the closure of original cracks and the friction between material particles, which has low frequency and weak energy. The other is the fracture-type acoustic emission event caused by the expansion of new cracks, and this kind of acoustic emission has relatively high frequency and energy. Two types of $\mathrm{AE}$ events correspond to friction and fracture mechanisms, respectively. Figure 10 shows the relationship between the peak frequency and the acoustic emission energy of the specimen at the end of the compaction stage (point $\mathrm{A}$ ), the crack initiation point (point $\mathrm{B}$ ), the dilatancy point (point $\mathrm{C}$ ), the peak stress point (point $\mathrm{D}$ ), and the failure point (point $\mathrm{E}$ ) under the initial confining pressure which is $5 \mathrm{MPa}$ and $20 \mathrm{MPa}$.

According to Figure 10, the peak frequency and energy of acoustic emission signals at different times with the same confining pressure have great differences. In Figures 10(a1), to $10(\mathrm{~d} 1)$, with the application of axial load, the energy value of the acoustic emission signal keeps increasing. The maximum acoustic emission energy at moment $\mathrm{A}$ is $28 \mathrm{mV} \cdot \mathrm{ms}$, the maximum value of acoustic emission energy is $420 \mathrm{mV} \cdot \mathrm{ms}$ at the moment of $\mathrm{C}$, and the maximum acoustic emission energy at moment $\mathrm{E}$ is as high as $4610 \mathrm{mV} \cdot \mathrm{ms}$, which is 171.79 times higher than that at the moment of A. At the same time, as the loading-applied AE highfrequency signal points increase, the frequencies of acoustic emission signals of the samples are concentrated in the range of $8.8 \sim 23.4 \mathrm{kHz}$ at the moment $\mathrm{A}$ and moment $\mathrm{B}$ (see Figures 10(a) and 10(b)), which are dominated by lowfrequency and low-energy friction-type acoustic emission events. At moment $\mathrm{C}$, a small number of high-frequency signal points appear in the sample, which indicates that before the crack initiation point, $\mathrm{AE}$ events are mainly induced by the crack closure and interparticle friction in the granite sample. At moments D and E (see Figures 10(d) and 10(e)), a large number of high-frequency signal points appear. At this time, the acoustic emission model gradually transform from low-frequency and low-energy frictiontype $\mathrm{AE}$ events to high-frequency and high-energy fracture-type $\mathrm{AE}$ events, and the above process is consistent with the deformation and damage process of the sample under triaxial loading. The AE signals of granite samples gradually evolve to high-frequency and high-energy regions under a low confining pressure. When the confining pressure is high, in Figures 10(d), the density of high-frequency and high-energy region points is the largest, while in Figure 10(e), the number of high-frequency and highenergy signal points is significantly reduced, and more intermediate frequency signals appear, which indicate that high confining pressure inhibits the generation of tension cracks.

5.1.3. The Relationship between RA and AF Parameters with Failure Mode. According to the research, the value of RA and average frequency (AF) in acoustic emission parameters can reflect the failure type of the rock material, where the value of RA can be obtained by dividing the rising time by the amplitude value of acoustic emission, and the average frequency $\mathrm{AF}$ is obtained by the ratio of ringing count and duration. Generally speaking, the $\mathrm{AE}$ signal has a low $\mathrm{AF}$ value and high RA value when the shear crack is initiated in the sample; otherwise, if the tensile crack is initiated, the $\mathrm{AE}$ event has a high AF value and low RA value [43], as shown in Figure 11.

The RA value and AF value of the granite samples were calculated, and the scatter distribution diagram is drawn, as shown in Figure 12.

As can be seen from the distribution of points in Figure 12, with the increase of confining pressure, the distribution region tends to approach the horizontal axis. In Figure 12(a), the points cover the entire longitudinal axis, which are mainly concentrated in the interval of $10<\mathrm{AF}<$ 80. At this time, the AE signal has a lower RA value and a higher AF value, which indicates that the tensile crack of the sample is developed, when the confining pressure is 0 $<\mathrm{RA}<40$. At this time, the difference between the acoustic emission signals AF and RA is small, and the tensile cracks and shear cracks are relatively developed in the sample; when the confining pressure is $15 \mathrm{MPa}$, the points are mainly concentrated near the horizontal axis and are dense relatively in the interval of $(0,40)$; the cracks produced by specimen failure are mainly shear cracks. In Figure 12(d), the points are all over the entire horizontal axis, the maximum value of AF decreases from 100 to about 70, and the RA value of the acoustic emission signal is much larger than the AF value. At this time, the shear crack of the sample is relatively developed, and the ultimate performance is typical shear failure. The failure modes of rock samples under different confining pressures determined above are consistent with the actual situation.

5.1.4. The Characteristic of $A E b$ Value under Different Confining Pressures. Acoustic emission is a phenomenon of acoustic waves monitored by the release of strain energy during rock deformation and failure. Therefore, the acoustic emission event can be regarded as a kind of microseismic activity $[44,45]$. Gutenberg and Richter [46] proposed the statistical relationship between earthquake magnitude and frequency distribution:

$$
\lg N=a-b M
$$




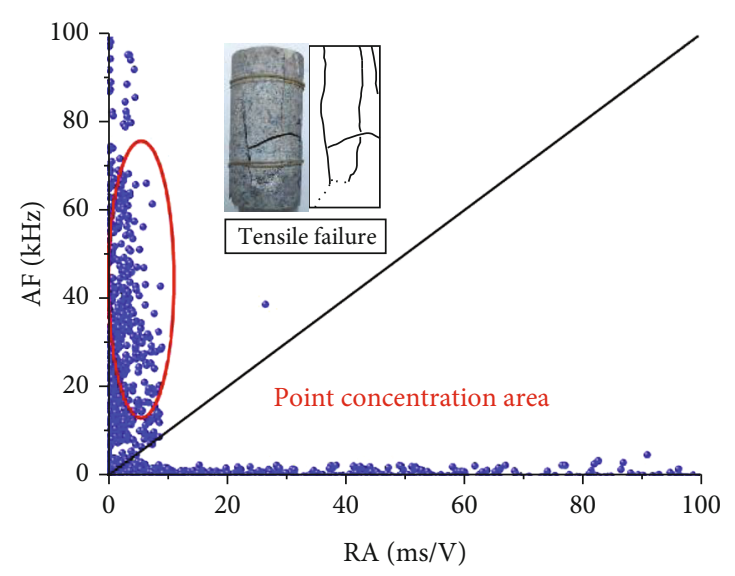

(a) $\sigma_{3}=5 \mathrm{MPa}$

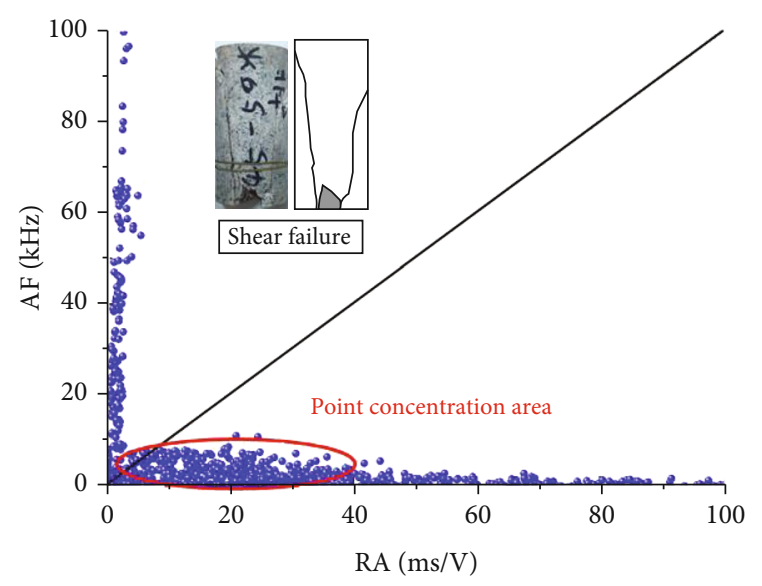

(c) $\sigma_{3}=15 \mathrm{MPa}$

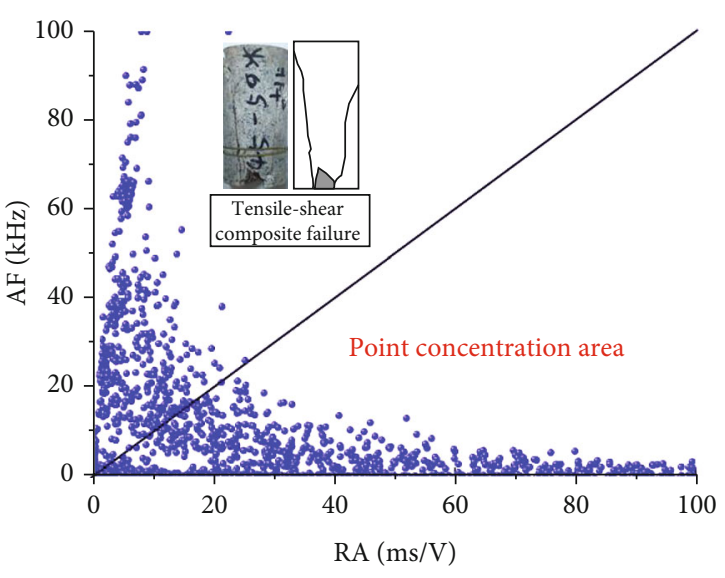

(b) $\sigma_{3}=10 \mathrm{MPa}$

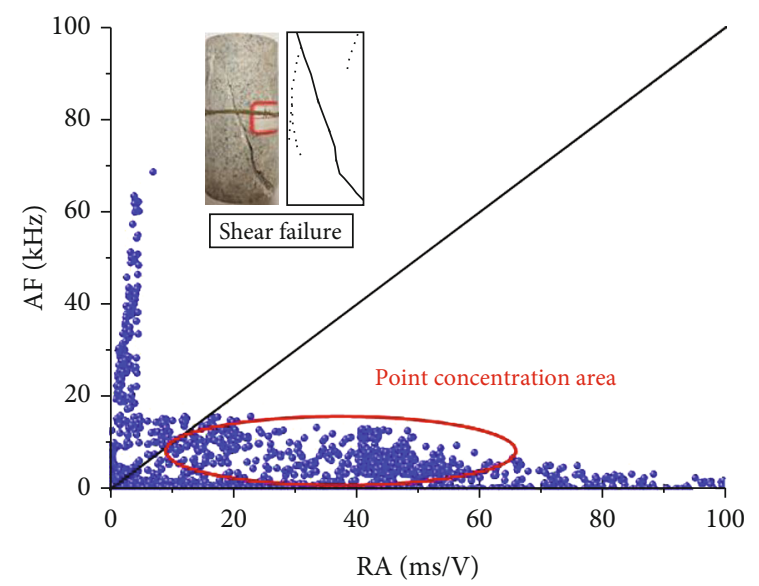

(d) $\sigma_{3}=20 \mathrm{MPa}$

FIGURE 12: Distribution of AE parameters of RA versus AF.

where $a$ and $b$ are constants related to seismic activity characteristics; $N$ is the number of earthquakes with magnitude in the range of $\Delta M$, which can be considered as acoustic emission events of samples; and $M$ is the magnitude of the earthquake, which can be replaced by the acoustic emission amplitude $(\mathrm{dB})$ divided by 20 ; formula (8) can be rewritten as

$$
\lg N=a-b\left(\frac{A_{\mathrm{dB}}}{20}\right)
$$

where $A_{\mathrm{dB}}(\mathrm{dB})$ is the amplitude of the acoustic emission signal, $N$ is the number of AE events, and $a$ and $b$ are constant. The $b$ value of acoustic emission is a measure of the change of crack development, and the overall value and change trend of the $b$ value are closely related to the internal crack development of rock. When the $b$ value of acoustic emission is large, which indicates that the number of small events increases, and the development of internal rock cracks is a gradual and stable propagation. When the value of $b$ is small, it means that the proportion of AE small events decreases, while the number of large events increases, which indicates that the crack inside the sample develops dramatically, and the rock may be damaged. In order to avoid large errors in the calculation, this paper selects $100 \mathrm{AE}$ signals as a group of data to calculate the $b$ value of AE by using the least-square method; the variation of the $b$ value of samples during the conventional triaxial loading is shown in Figure 13.

As can be seen from Figure 13, in the early stages of loading, the $b$ values of the sample under different confining pressures were low, and the AE amplitude was high and typically around $10-20 \mathrm{~dB}$. Low $b$ values and high amplitudes are due to the original holes and cracks in the rock samples which were compacted. In the elastic deformation stage, the $\mathrm{AE}$ amplitudes were low and below $10 \mathrm{~dB}$. The $b$ value of acoustic emission suddenly increases to its maximum value, and it fluctuates slightly near the maximum value. This indicates that the number of small $\mathrm{AE}$ events is increasing, the proportion of large and small events changes little at this stage, the development of internal cracks in the rock is slow, and the development of original cracks and regenerated cracks with different scales is relatively stable. As the load continues to increase, the $b$ value of acoustic emission begins to decrease and reaches the minimum value at the peak 


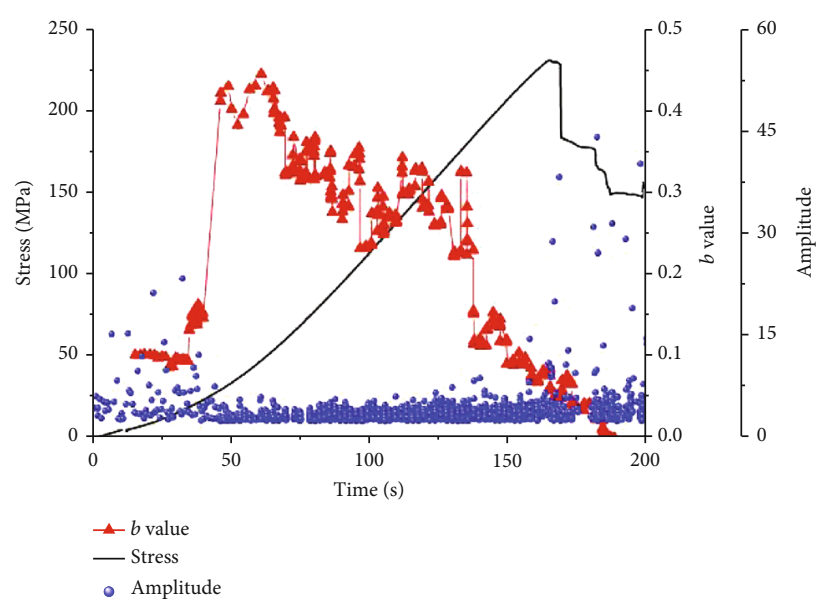

(a) $\sigma_{3}=5 \mathrm{MPa}$

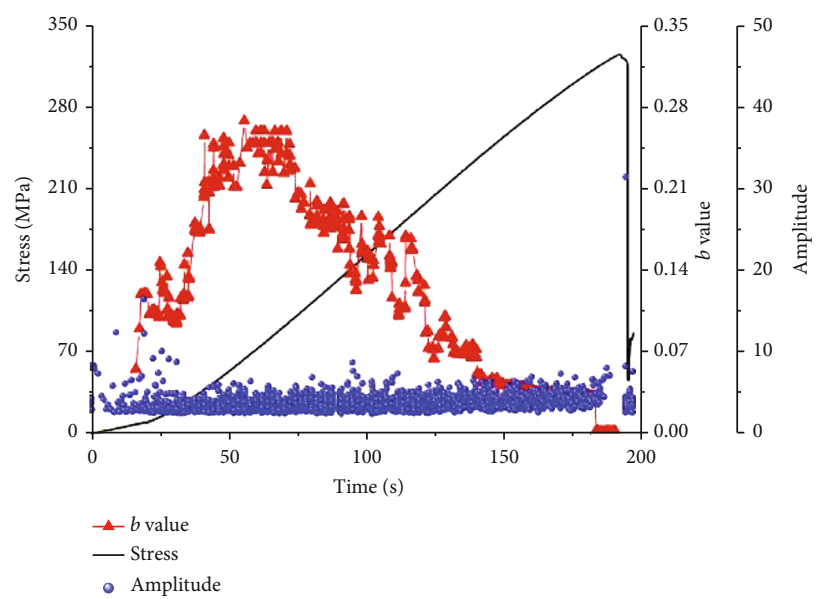

(c) $\sigma_{3}=15 \mathrm{MPa}$

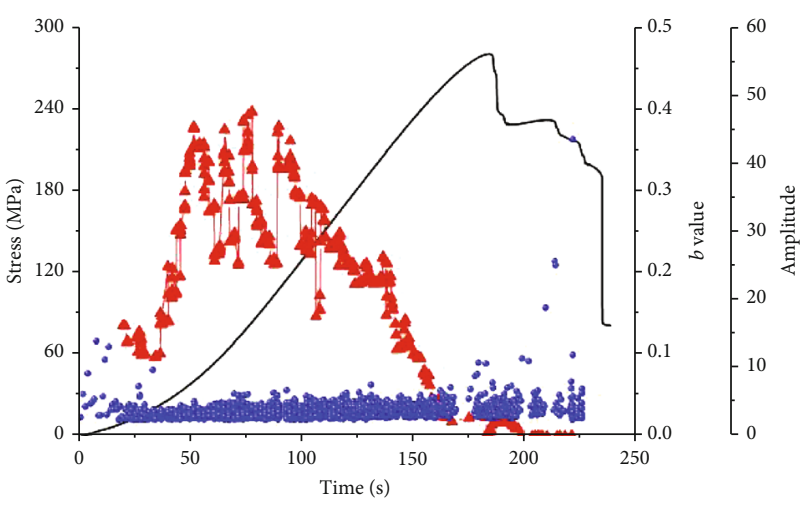

$\perp b$ value

- Stress

- Amplitude

(b) $\sigma_{3}=10 \mathrm{MPa}$

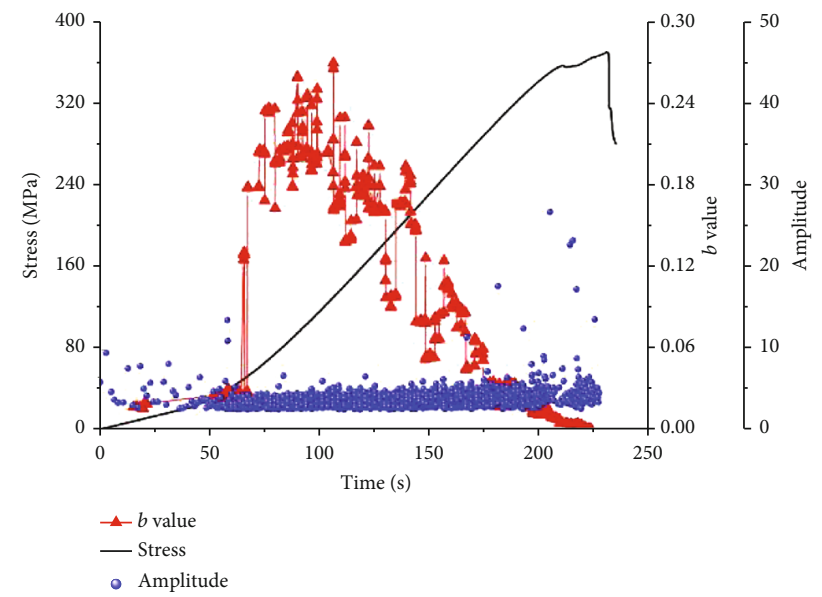

(d) $\sigma_{3}=20 \mathrm{MPa}$

FIgURE 13: The relationship between time and $b$ value under different confining pressures.

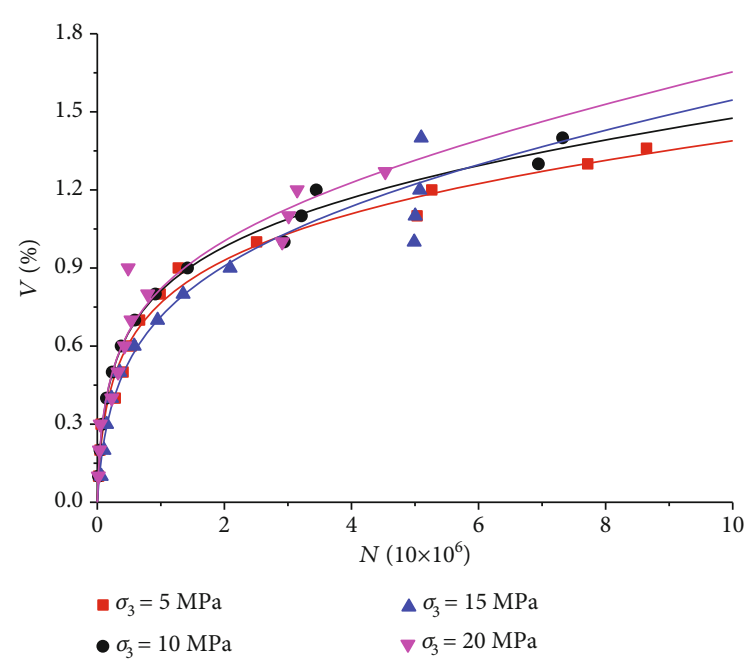

Figure 14: The relationship between $N$ and $V$.
TABLe 1: Fitting results of $V$ and $N$.

\begin{tabular}{lcccc}
\hline Confining pressure $(\mathrm{MPa})$ & $a$ & $c$ & $q$ & $R^{2}$ \\
\hline 5 & 0.0127 & 0.224 & 27.822 & 0.982 \\
10 & 0.0170 & 0.224 & 33.846 & 0.992 \\
15 & 0.0307 & 0.248 & 14.712 & 0.966 \\
20 & 0.0384 & 0.214 & 37.594 & 0.976 \\
\hline
\end{tabular}

stress. In this process, the proportion of $\mathrm{AE}$ major events keeps increasing, the internal cracks of the sample accelerate the expansion, and the number of large-size cracks gradually increases, and finally, the failure occurs.

As seen Figure 13(a), the maximum value of the $b$ value is 0.44 , the $b$ value of acoustic emission drops sharply at $79 \%$ $\sigma_{c}$, and then, the rate of decline is $3.65 \times 10^{-3} \mathrm{~s}^{-1}$. As seen Figure $13(\mathrm{~d})$, the maximum value of the $b$ value is 0.28 , which begins to decrease at $59.3 \% \sigma_{c}$, but the reduction rate is $9.46 \times 10^{-4} \mathrm{~s}^{-1}$. The above phenomenon is mainly due to the insufficient development of deformation and damage in the specimen under a small confining pressure, which shows 


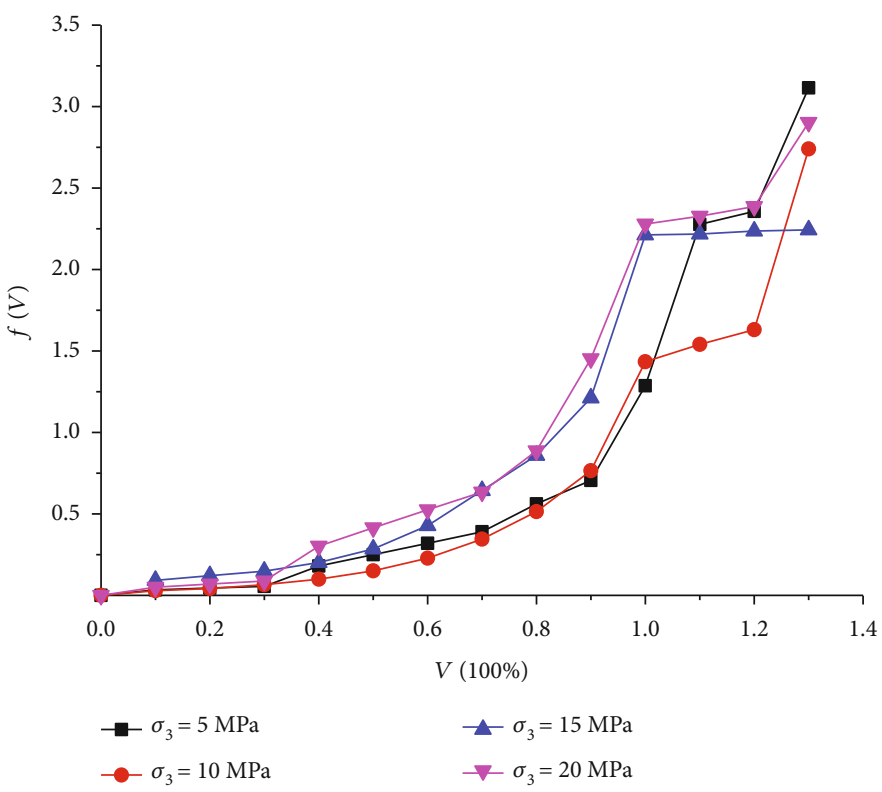

Figure 15: The relationship between $f(V)$ and $V$ under different confining pressures.

the characteristics of brittle failure. Therefore, during the deformation and failure process, the $b$ value is larger, and the $b$ value will drop suddenly and decrease rapidly. In the case of a large confining pressure, due to the restraint of confining pressure and high stress level, the cracks of the specimen are fully developed and exhibit well ductility during the deformation and failure process. At this time, the $b$ value is small, the decrease time of $b$ value is early, and the rate of decrease is slower.

5.2. Damage Model of Granite under Triaxial Stress. From the above study, it is clear that acoustic emission parameters can qualitatively characterize the damage and failure of materials to a certain extent $[47,48]$. The probability-density function $f(V)$ was introduced into this paper [2] to establish the relationship between acoustic emission events and corresponding stress level quantitatively, as shown:

$$
f(V) d V=\frac{d N}{N_{0}},
$$

where $V$ is the stress levels; it can be obtained by dividing the stress at a certain moment by the strength of the granite specimen under the corresponding confining pressure, $N$ is the number of cumulative events, and $N_{0}$ is the number of total cumulative events. The relationship between $V$ and $N$ is shown in the following formula [49]:

$$
V=\mathrm{aN}+c \ln (1+q N) .
$$

Based on equation (11), the conventional triaxial compression test data of the sample were fitted, and the fitting results are shown in Figure 14.

As can be seen from Table 1, the correlation coefficient $R^{2}$ of the fitting results is distributed between 0.966 and
0.992, all of which are greater than 0.950. It indicates that the stress levels $V$ and the number of cumulative events $N$ under different confining pressures have a good logarithmic relationship, and the values of $a, c$, and $q$ of equation (11) under different confining pressures were obtained through fitting. We substitute (11) into formula (10), through integral operation, as shown:

$$
f(V)=\frac{1}{N_{0}}\left(\frac{1+q N}{a+c q+a q N}\right) .
$$

From equation (12) and the fitting result in Figure 13, the relationship between $f(V)$ and $V$ can be obtained as shown in Figure 15.

In order to study the damage variables $D$ of granite in the postpeak stage, the stress level in the postpeak stage is defined as follows:

$$
V=1+\frac{\sigma_{\max }-\sigma}{\sigma_{\max }}
$$

where $\sigma_{\max }$ is the peak stress of the granite specimen under the corresponding initial confining pressure (MPa). $\sigma$ is the stress of the granite specimen at a certain point in the postpeak stage (MPa).

The damage variable $D$ of the granite specimen can be obtained by integrating the probability-density function $f$ $(V)$ as shown:

$$
D=\int_{0}^{V} f(V) d V
$$

The damage curves of granite under different confining pressures can be obtained using Origin software to 


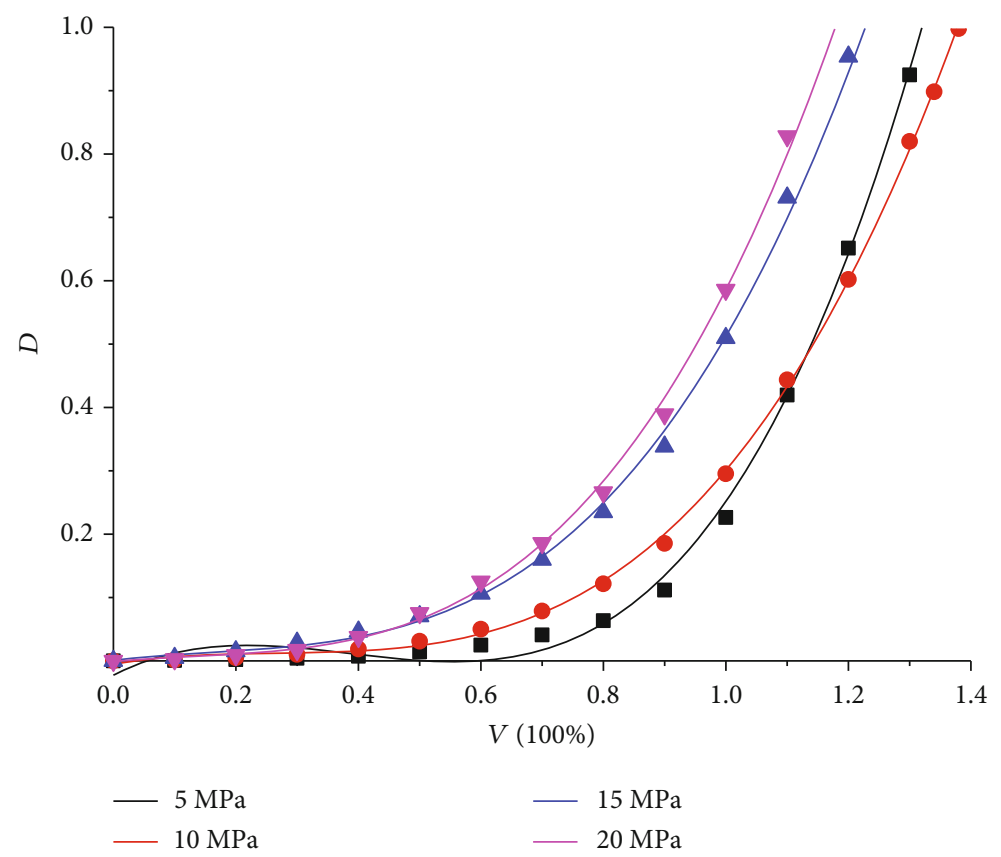

Figure 16: Damage curves of granite samples under different confining pressures.

integrate the $f(V)-V$ curve, as shown in Figure 16 and formula (15).

$$
\begin{aligned}
& \sigma_{3}=5 \mathrm{MPa}: D=1.350 V^{3}-1.570 V^{2}+0.494 V-0.023, R^{2}=0.997, \\
& \sigma_{3}=10 \mathrm{MPa}: D=0.712 V^{3}-0.573 V^{2}+0.167 V-0.005, R^{2}=0.999, \\
& \sigma_{3}=15 \mathrm{MPa}: D=0.761 V^{3}-0.369 V^{2}+0.119 V-0.001, R^{2}=0.998, \\
& \sigma_{3}=20 \mathrm{MPa}: D=0.783 V^{3}-0.313 V^{2}+0.088 V-0.001, R^{2}=0.999 .
\end{aligned}
$$

It can be seen from Figure 16 and formula (15) that there was a positively proportional linear relationship between $D$ and the cubic polynomial in $V$; the correlation coefficients obtained by fitting are all greater than 0.99 . As can be seen from Figure 16, the larger the initial confining pressure is, the larger the rock damage parameter $D$ is under the same stress level, which is caused by the rock which will appear as a stick-slip phenomenon under the high confining pressure. When the stress level is greater than 1.1 , the damage variable of the specimen at $5 \mathrm{MPa}$ is greater than that at $10 \mathrm{MPa}$.

\section{Conclusion}

Conventional triaxial compression tests under different confining pressure were carried out in this paper. The following main results are obtained through the test results:

(1) The elastic modulus and plastic deformation of the granite sample are small, and the brittleness characteristics are significant when the confining pressure of the sample is low; conversely, the granite sample has obvious compression hardness and ductile characteristics. The peak stress and strain of the granite specimen increase linearly with the increase of the confining pressure of the sample. According to the Mohr-Coulomb strength criterion, the cohesion of the granite sample is $29.37 \mathrm{MPa}$ and the internal friction angle is $54.23^{\circ}$

(2) The crack initiation $\left(\sigma_{\mathrm{ci}}\right)$ stress and dilatancy stress $\left(\sigma_{c d}\right)$ of hard rock were determined based on the law of linear energy dissipation, which concluded that the $\sigma_{\mathrm{ci}}$ and $\sigma_{\mathrm{cd}}$ of granite specimens increase with the increase of confining pressure. Confining pressure has a significant promoting effect on the energy storage capacity of granite samples. At the crack initiation point and expansion point, the total energy and elastic strain energy of the specimen increase with the increase of the confining pressure, but the dissipated energy is less affected by the confining pressure. The value of each energy in the sample increases significantly with the increase of initial confining pressure at the peak stress. And the higher the confining pressure is, the faster the energy release of the sample is in the failure stage

(3) The ringing counts and cumulative ringing count increase rapidly to the maximum value near the peak stress while the confining pressure is small, and the specimen suddenly fails in a very short time. Conversely, when the ringing counts and cumulative ring counts increase more smoothly, the acoustic emission signal becomes active at the expansion point and the deformation damage of the sample is fully developed. Before the crack initiation point, AE signals are mainly low-energy and low-frequency friction-type $\mathrm{AE}$ events, while after the dilatation point, AE signals of samples are mainly high- 
frequency and high-energy fracture-type AE events, and the acoustic emission signal has greater energy when the confining pressure is larger

(4) Typical tensile failure fracture occurs in granite samples under the low confining pressure, and tensionshear composite failure or typical shear failure is found in granite samples under high confining pressure, which is consistent with the failure mode of granite samples judged by acoustic emission parameters according to the distribution of characteristic values of $\mathrm{AE}$ parameters RA and AF. In the case of a low confining pressure, the acoustic emission $b$ value of the granite sample is large, there will be a sudden drop, the decrease time is late, and the decrease rate is large. Under the same stress level, the larger the initial confining pressure is, the larger the damage variable $D$ is

\section{Data Availability}

The data used to support the findings of this study are available from the corresponding author upon request.

\section{Conflicts of Interest}

The authors declare that there are no conflicts of interest regarding the publication of this paper.

\section{Acknowledgments}

This research was funded by the National Natural Science Foundation of China (51778215) and China Postdoctoral Science Foundation Funded Project (No. 2018M631114). The authors greatly appreciate the financial support from funding bodies.

\section{References}

[1] H. Han, D. Fukuda, H. Liu et al., "Combined finite-discrete element modellings of rockbursts in tunnelling under high in-situ stresses," Computers and Geotechnics, vol. 137, article 104261, 2021.

[2] Y. Wu, S. Li, D. Wang, and G. Zhao, "Damage monitoring of masonry structure under in-situ uniaxial compression test using acoustic emission parameters," Construction and Building Materials, vol. 215, pp. 812-822, 2019.

[3] M. He, F. Ren, and D. Liu, "Rockburst mechanism research and its control," International Journal of Mining Science and Technology, vol. 28, no. 5, pp. 829-837, 2018.

[4] J. Wang, G. Chen, Y. Xiao, S. Li, Y. Chen, and Z. Qiao, "Effect of structural planes on rockburst distribution: case study of a deep tunnel in Southwest China," Engineering Geology, vol. 292, article 106250, 2021.

[5] R. Xue, Z. Liang, and N. Xu, "Rockburst prediction and analysis of activity characteristics within surrounding rock based on microseismic monitoring and numerical simulation," International Journal of Rock Mechanics and Mining Sciences, vol. 142, article 104750, 2021.
[6] V. Kallimogiannis, H. Saroglou, and G. Tsiambaos, "Study of cracking process in granite," Procedia Engineering, vol. 191, pp. 1108-1116, 2017.

[7] S. Wang, L. Huang, and X. Li, “Analysis of rockburst triggered by hard rock fragmentation using a conical pick under high uniaxial stress," Tunnelling and Underground Space Technology, vol. 96, article 103195, 2020.

[8] C. D. Martin and N. A. Chandler, "The progressive fracture of Lac du Bonnet granite," International Journal of Rock Mechanics and Mining Sciences \& Geomechanics Abstracts, vol. 31, no. 6, pp. 643-659, 1994.

[9] Y. Zong, L. Han, J. Wei, and S. Wen, "Mechanical and damage evolution properties of sandstone under triaxial compression," International Journal of Mining Science and Technology, vol. 26, no. 4, pp. 601-607, 2016.

[10] T. Zhou, Y. Qin, Q. Ma, and J. Liu, “A constitutive model for rock based on energy dissipation and transformation principles," Arabian Journal of Geosciences, vol. 12, no. 15, p. 492, 2019.

[11] D. Li, Z. Sun, T. Xie, X. Li, and P. G. Ranjith, "Energy evolution characteristics of hard rock during triaxial failure with different loading and unloading paths," Engineering Geology, vol. 228, pp. 270-281, 2017.

[12] H. P. Xie, J. F. Liu, Y. Ju, J. Li, and L. Z. Xie, "Fractal property of spatial distribution of acoustic emissions during the failure process of bedded rock salt," International Journal of Rock Mechanics and Mining Sciences, vol. 48, no. 8, pp. 13441351, 2011.

[13] H. Xie, L. Li, Y. Ju, R. D. Peng, and Y. M. Yang, "Energy analysis for damage and catastrophic failure of rocks," Science China Technological Sciences, vol. 54, Supplement 1, pp. 199209, 2011.

[14] H. P. Xie, Y. Ju, and L. Li, "Criteria for strength and structural failure of rocks based on energy dissipation and energy release principles," Chinese Journal of Rock Mechanics and Engineering, vol. 17, pp. 3003-3010, 2005.

[15] Y. Tian and R. G. Yu, "Energy analysis of limestone during triaxial compression under different confining pressures," Rock and Soil Mechanics, vol. 35, no. 1, pp. 118-122, 2014.

[16] Z. Z. Zhang and F. GAO, "Confining pressure effect on rock energy," Chinese Journal of Rock Mechanics and Engineering, vol. 34, no. 1, pp. 1-11, 2015.

[17] H. Sun, L. Ma, W. Liu, A. J. S. Spearing, J. Han, and Y. Fu, "The response mechanism of acoustic and thermal effect when stress causes rock damage," Applied Acoustics, vol. 180, article 108093, 2021.

[18] Q. Wang, J. Chen, J. Guo, Y. Luo, H. Wang, and Q. Liu, "Acoustic emission characteristics and energy mechanism in karst limestone failure under uniaxial and triaxial compression," Bulletin of Engineering Geology and the Environment, vol. 78, no. 3, pp. 1427-1442, 2019.

[19] C. Khazaei, J. Hazzard, and R. Chalaturnyk, "Damage quantification of intact rocks using acoustic emission energies recorded during uniaxial compression test and discrete element modeling," Computers and Geotechnics, vol. 67, pp. 94-102, 2015.

[20] D. S. B. S. Eberhardt, D. Stead, B. Stimpson, and R. S. Read, "Identifying crack initiation and propagation thresholds in brittle rock," Canadian Geotechnical Journal, vol. 35, no. 2, pp. 222-233, 1998.

[21] P. Ganne, A. Vervoort, and M. Wevers, "Quantification of prepeak brittle damage: correlation between acoustic emission 
and observed micro-fracturing," International Journal of Rock Mechanics and Mining Sciences, vol. 44, no. 5, pp. 720-729, 2007.

[22] M. Cai, P. K. Kaiser, H. Morioka et al., "FLAC/PFC coupled numerical simulation of AE in large-scale underground excavations," International Journal of Rock Mechanics and Mining Sciences, vol. 44, no. 4, pp. 550-564, 2007.

[23] X. G. Zhao, M. Cai, J. Wang, P. F. Li, and L. K. Ma, “Objective determination of crack initiation stress of brittle rocks under compression using ae measurement," Rock Mechanics and Rock Engineering, vol. 48, no. 6, pp. 2473-2484, 2015.

[24] L. M. Zhang, S. Q. Ma, M. Y. Ren, S. Q. Jiang, Z. Q. Wang, and J. L. Wang, "Acoustic emission frequency and $b$-value characteristics in rock failure process under various confining pressures," Chinese Journal of Rock Mechanics and Engineering, vol. 34, no. 10, pp. 2057-2063, 2015.

[25] C. A. Tang and X. H. Xu, "Evolution and propagation of material defects and Kaiser effect function," Journal of Seismological Research, vol. 13, no. 2, pp. 203-213, 1990.

[26] E. Eberhardt, D. Stead, and B. Stimpson, "Quantifying progressive pre-peak brittle fracture damage in rock during uniaxial compression," International Journal of Rock Mechanics and Mining Sciences, vol. 36, no. 3, pp. 361-380, 1999.

[27] B. X. Liu, J. L. Huang, Z. Y. Wang, and L. Liu, "Study on damage evolution and acoustic emission character of coal-rock under uniaxial compression," Chinese Journal of Rock Mechanics and Engineering, vol. 28, Supplement 1, pp. 32343238, 2009.

[28] M. Cai, H. Morioka, P. K. Kaiser et al., "Back-analysis of rock mass strength parameters using AE monitoring data," International Journal of Rock Mechanics and Mining Sciences, vol. 44, no. 4, pp. 538-549, 2007.

[29] D. Triantis, "Acoustic emission monitoring of marble specimens under uniaxial compression. Precursor phenomena in the near-failure phase," Procedia Structural Integrity, vol. 10, pp. 11-17, 2018.

[30] S. Yang, H. Jing, and S. Wang, "Experimental investigation on the strength, deformability, failure behavior and acoustic emission locations of red sandstone under triaxial compression," Rock Mechanics and Rock Engineering, vol. 45, no. 4, pp. 583-606, 2012.

[31] J. Guo, P. Liu, J. Fan, X. Shi, and X. Huang, "Influence of confining pressure unloading rate on the strength characteristics and fracture process of granite using lab tests," Advances in Materials Science and Engineering, vol. 2021, Article ID 7925608, 16 pages, 2021.

[32] Q. Yin, R. Liu, H. Jing, H. Su, L. Yu, and L. He, "Experimental study of nonlinear flow behaviors through fractured rock samples after high-temperature exposure," Rock Mechanics and Rock Engineering, vol. 52, no. 9, pp. 2963-2983, 2019.

[33] P. Li, X. Li, Z. Guo, L. Ma, and J. Wang, "Variation of strength parameters of Beishan granite under triaxial compression," Chinese Journal of Rock Mechanics and Engineering, vol. 36, no. 7, pp. 1599-1610, 2017.

[34] C. D. Su and Z. H. Zhang, "Analysis of plastic deformation and energy property of marble under pseudo-triaxial compression," Chinese Journal of Rock Mechanics and Engineering, vol. 27, no. 1, pp. 136-142, 2008.

[35] G. Q. Guo, X. L. Liu, and C. S. Qiao, "Experimental study of mechanical properties and energy mechanism of karst limestone under natural and saturated states," Chinese Journal of
Rock Mechanics and Engineering, vol. 33, no. 2, pp. 269-308, 2014.

[36] Y. Yang, Y. Ju, F. Li, F. Gao, and H. Sun, "The fractal characteristics and energy mechanism of crack propagation in tight reservoir sandstone subjected to triaxial stresses," Journal of Natural Gas Science and Engineering, vol. 32, pp. 415-422, 2016.

[37] N. Li, Y. Zou, S. Zhang et al., "Rock brittleness evaluation based on energy dissipation under triaxial compression," Journal of Petroleum Science and Engineering, vol. 183, article 106349, 2019.

[38] T. Shiotani, M. Ohtsu, and K. Ikeda, "Detection and evaluation of $\mathrm{AE}$ waves due to rock deformation," Construction and Building Materials, vol. 15, no. 5-6, pp. 235-246, 2001.

[39] N. B. Burud and J. M. C. Kishen, "Response based damage assessment using acoustic emission energy for plain concrete," Construction and Building Materials, vol. 269, article 121241, 2021.

[40] Z. Moradian, H. H. Einstein, and G. Ballivy, "Detection of cracking levels in brittle rocks by parametric analysis of the acoustic emission signals," Rock Mechanics and Rock Engineering, vol. 49, no. 3, pp. 785-800, 2016.

[41] X. Lei and T. Satoh, "Indicators of critical point behavior prior to rock failure inferred from pre- failure damage," Tectonophysics, vol. 431, no. 1-4, pp. 97-111, 2007.

[42] K. Zhao, D. Yang, C. Gong, Y. Zhuo, X. Wang, and W. Zhong, "Evaluation of internal microcrack evolution in red sandstone based on time-frequency domain characteristics of acoustic emission signals," Construction and Building Materials, vol. 260, article 120435, 2020.

[43] M. C. He, F. Zhao, S. Du, and M. J. Zheng, "Rockburst characteristics based on experimental tests under different unloading rates," Rock and Soil Mechanics, vol. 35, no. 10, pp. 2737-2747, 2014.

[44] Z. Zhang, R. Zhang, H. Xie, J. Liu, and P. Were, "Differences in the acoustic emission characteristics of rock salt compared with granite and marble during the damage evolution process," Environmental Earth Sciences, vol. 73, no. 11, pp. 6987-6999, 2015.

[45] C. Müller, T. Frühwirt, D. Haase, R. Schlegel, and H. Konietzky, "Modeling deformation and damage of rock salt using the discrete element method," International Journal of Rock Mechanics and Mining Sciences, vol. 103, pp. 230-241, 2018.

[46] B. Gutenberg and C. F. Richter, "Frequency of earthquakes in California," Bulletin of the Seismological Society of America, vol. 34, no. 4, pp. 185-188, 1994.

[47] X. Chi, K. Yang, and Z. Wei, "Investigation of energy and damage evolutions in rock specimens with large-scale inclined prefabricated cracks by uniaxial compression test and $\mathrm{AE}$ monitoring," Advances in Civil Engineering, vol. 2020, Article ID 8887543, 12 pages, 2020.

[48] A. Ishibashi, K. Matsuyama, N. Alver, T. Suzuki, and M. Ohtsu, "Round-robin tests on damage evaluation of concrete based on the concept of acoustic emission rates," Materials and Structures, vol. 49, no. 7, pp. 2627-2635, 2016.

[49] X. Zhou and J. Zhang, "Damage progression and acoustic emission in brittle failure of granite and sandstone," International Journal of Rock Mechanics and Mining Sciences, vol. 143, article 104789, 2021. 